\title{
Revision of the family Carabodidae (Acari: Oribatida) XIV. Phyllocarabodes costaricensis sp. nov. from Costa Rica and Zimbabweae kenyaensis sp. nov. from Kenya
}

\author{
Nestor Fernandez $\mathbb{D}^{\mathrm{a}}{ }^{\mathrm{a} b}$, Pieter Theron $\mathbb{B}^{\mathrm{b}}$, Sergio Leiva ${ }^{\mathrm{c}}$ and Louwrens Tiedt ${ }^{\mathrm{d}}$ \\ aNational Council of Scientific and Technological Research (CONICET). Evolutive Genetic Laboratory FCEQyN, Misiones National University, Posadas \\ Misiones, Argentina; ${ }^{b}$ Research Unit for Environmental Sciences and Management, North-West University, Potchefstroom, South Africa; ' National \\ Institute Agricultural Technology (INTA), Experimental Rural Agency, Aimogasta; 'Laboratory for Electron Microscopy, North-West University, \\ Potchefstroom, South Africa
}

\begin{abstract}
Phyllocarabodes costaricensis sp. nov. and Zimbabweae kenyaensis sp. nov. are described using optical microscopy and scanning electron microscopy. For Phyllocarabodes costaricensis sp. nov., a detailed description is provided, along with a discussion on the position of Phyllocarabodes as subgenus within the genus Carabodes. We conclude that Phyllocarabodes, with a series of particular characteristics, is a distinct genus and not a subgenus of Carabodes. The genus Phyllocarabodes is redefined. Zimbabweae kenyaensis sp. nov. is closely related to Zimbabweae pluosiae Fernandez, Theron, Leiva 2016, exhibiting the following distinctive characters: shape of prodorsal zone promontories different; associated structures and trajectory of circumgastric depression dissimilar; pedotectum I, pedotectum II and discidium differ in shape; dissimilar disposition of promontories; differences in ventral and epimeral zones.
\end{abstract}

http://www.zoobank.org/urn:Isid:zoobank.org:pub:7B0F4768-944E-46B0-A11A-8769FFE3E5D9

\section{ARTICLE HISTORY}

Received 2 May 2017 Accepted 4 August 2017

Published online 25 August 2017

\section{KEYWORDS}

Carabodidae; systematics; Phyllocarabodes; Carabodes; problematic

\section{Introduction}

The taxonomy of the family Carabodidae has historically been beset by many problems in the genera the authors have studied over the past few years (Fernandez et al. 2013a, 2013b, 2013c; Fernandez et al. 2014a, 2014b, 2016). The case of Phyllocarabodes, however, is a veritable imbroglio.

Important remarks: (1) type material was not available for study; (2) incomplete and controversial descriptions by the same authors; (3) taxonomic changes made without justification.

The description of the genus Phyllocarabodes by Balogh and Mahunka (1969b) was somewhat vague and incomplete. In 1986, Mahunka redefined the genus, with a contradictory description with several aspects opposite to the original description given by Balogh and Mahunka (1969b). In 1986, Balogh P. described a new species, Phyllocarabodes ornatus and made several comparisons with the type species, several of them contradictory.

Subías (2004, updated 2017) included the genus Phyllocarabodes as subgenus of Carabodes without providing an explanation for doing so.

We analysed the preceding papers and compared them to our results of the description of Phyllocarabodes costaricensis sp. nov. to clarify the taxonomic situation of Phyllocarabodes and determine if it is a subgenus of Carabodes or not.

The second species described in this article is Zimbabweae kenyaensis sp. nov., collected in Kenya.

\section{Materials and methods}

Specimens studied by means of light microscopy followed the techniques described by Grandjean (1949) and Krantz and Walter (2009). Specimens studied with scanning electron microscope (SEM) followed the techniques of (Alberti and Fernandez 1988, 1990a, 1990b; Alberti et al. 1991, 1997, 2007; Fernandez et al. 1991). Equipment used is that of Fernandez et al. (2016).
For Zimbabweae kenyaensis sp. nov., the complexity of structures is evident in SEM micrographs (Figure 46-72). For ease of understanding and to facilitate observation, only the cuticular thickenings were indicated in drawings.

\section{Morphological terminology}

Morphological terms and abbreviations used are those developed by Grandjean (1928-1974) (cf. Travé and Vachon 1975; Norton \& Behan-Pelletier (in Krantz and Walter 2009; Fernandez et al. 2013a, 2013b, 2013c, 2014a, 2014b). For setal types Evans (1992) and for ornamentation of cuticular surfaces Murley (1951) (In: Evans op.cit., 9) were used. The following are added: prodorsal longitudinal ridge (p.l.r); promontories (prm), used as: prm la, prm Im, prm Ip, prm $h_{1}$, prm $h_{2}$, prm $h_{3}$, prm $p_{3}$, prm $p_{2}$, prm $p_{1}$ (promontories where the respective setae are inserted); transverse posterior prodorsal furrow (t.p.p.f); transverse series of small aggenital promontories (t.ag.p).

\section{New taxon description Phyllocarabodes costaricensis sp. nov.}

(Figures 1-45)

\section{Etymology}

The specific epithet "costaricensis" is derived from Costa Rica, country of origin of the type material.

\section{Material examined}

Holotype: Female "CR 0978 Tu 11 Costa Rica Turrialba forêt naturelle du catie alt.560 m. Triage d'humus côté est surface nid d'Atta au pied de Castilla elastica 1.IX. 1978. LEG P. WERNER", material deposited in the Collection of the Natural History Museum of Geneva (NHMG), Switzerland; preserved in $70 \%$ ethanol.

Paratype: Two adult females, same locality and date as Holotype; deposited in Collection of NHMG; preserved in $70 \%$ ethanol. Material studied using SEM: three specimens, not deposited. 

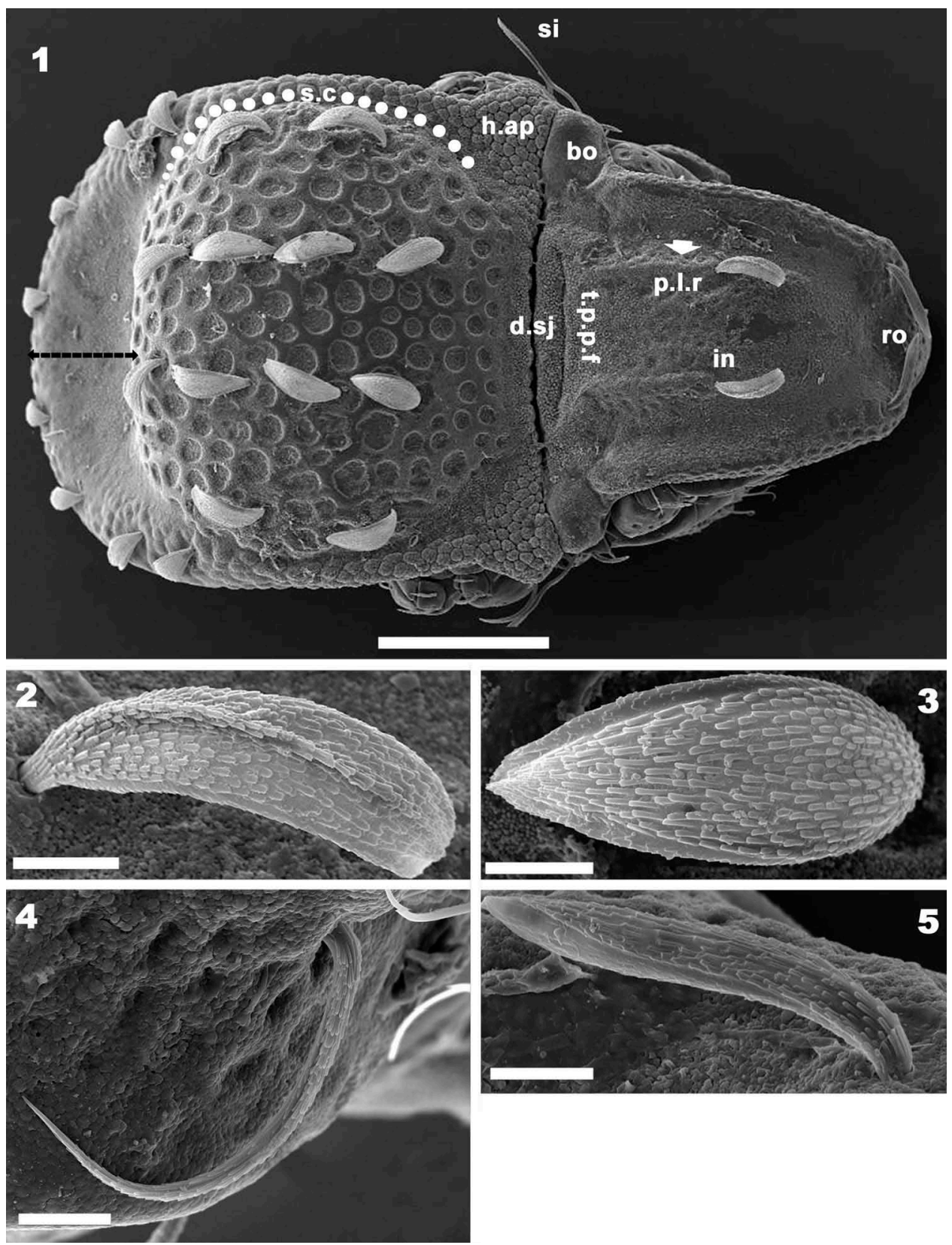

Figure 1-5. Phyllocarabodes costaricensis sp. nov. Adult female, SEM observations. 1. dorsal view; 2. interlamellar setae; 3. notogastral setae; 4. lamellar setae; 5. rostral setae. Abbreviations: see section on "Material and methods". Scale bars: $1=100 \mu \mathrm{m} ; 2-5=10 \mu \mathrm{m}$.

\section{Diagnosis (adult female)}

Setation: in setae, Salix leaf-shaped; ro setae elongate leaf-shaped: le setae, long phylliform, small dentitions; notogastral, adanal setae ovoid leaf-shaped, rugous margin; genital setae (three first pairs), setiform with longitudinal ribs; genital setae (last three pairs) flagelliform; epimeric setae, elongate barbate; anal setae, spiniform. Prodorsum elongated; posterior prodorsal depression absent. Prodorsal longitudinal ridge bearing insertions of the interlamellar setae; bothridium rounded, with bothridial opening curling to resemble a mouse ear. Tutorium: large curving lamina, with aligned ventrally dentitions. Pedotectum II, small rectangular lamina. Notogaster, light bulb-shaped; 10 pairs of setae with particular disposition; circumgastric furrow incomplete. Epimeral setal formulae 1-1-3-3; setae $3 b, 3 c$ situated more or less parallel, close to each other. Six pairs of genital setae. Lyrifissure iad lateral of $\mathrm{ad}_{3}$ setae.

\section{Description}

Measurements. SEM $460 \mu \mathrm{m}(455-466) \times 183 \mu \mathrm{m}$ (177-194) $(n=3)$. Light microscopy: $463 \mu \mathrm{m}(458-472) \times 184 \mu \mathrm{m}(179-$ 194) $(n=3)$.
Shape. Elongate oval (Figures 1 and 6).

Colour. Specimens without cerotegument: brown to dark brown when observed in reflected light.

Cerotegument. Present: prodorsum, notogaster and ventral region. Slightly granulated layer: prodorsal region near in setae, notogaster marginal zone, subcapitulum, bothridial zone (Figures 15, 16, 25, 35 and 36); layer of fine pustules: central notogastral zone, genital plate, aggenital zone, prodorsum posterior zone, humeral apophysis, epimeral zone (Figures 12, 13, 19, $20,27,30$ and 31 ).

Integument. Microsculpture. Foveate: notogastral elevated zone (Figures 1, 9, 19 and 20); colliculate: marginal zone, extending from h.ap to posterior marginal zone where notogastral lateral setae are situated (Figures 1, 10, 12, 13, 18 and 27); granulate: zone of s.c (Figures 9, 10, 12 and 16), bothridial zone (Figures 12 and 13); anterior and posterior zones of $d . s j$ (Figures 1 and 12); small foveate (Figures 9 and 22): lateral prodorsal margin, in front insertions of ro setal, prodorsal zone between prodorsal longitudinal ridge 


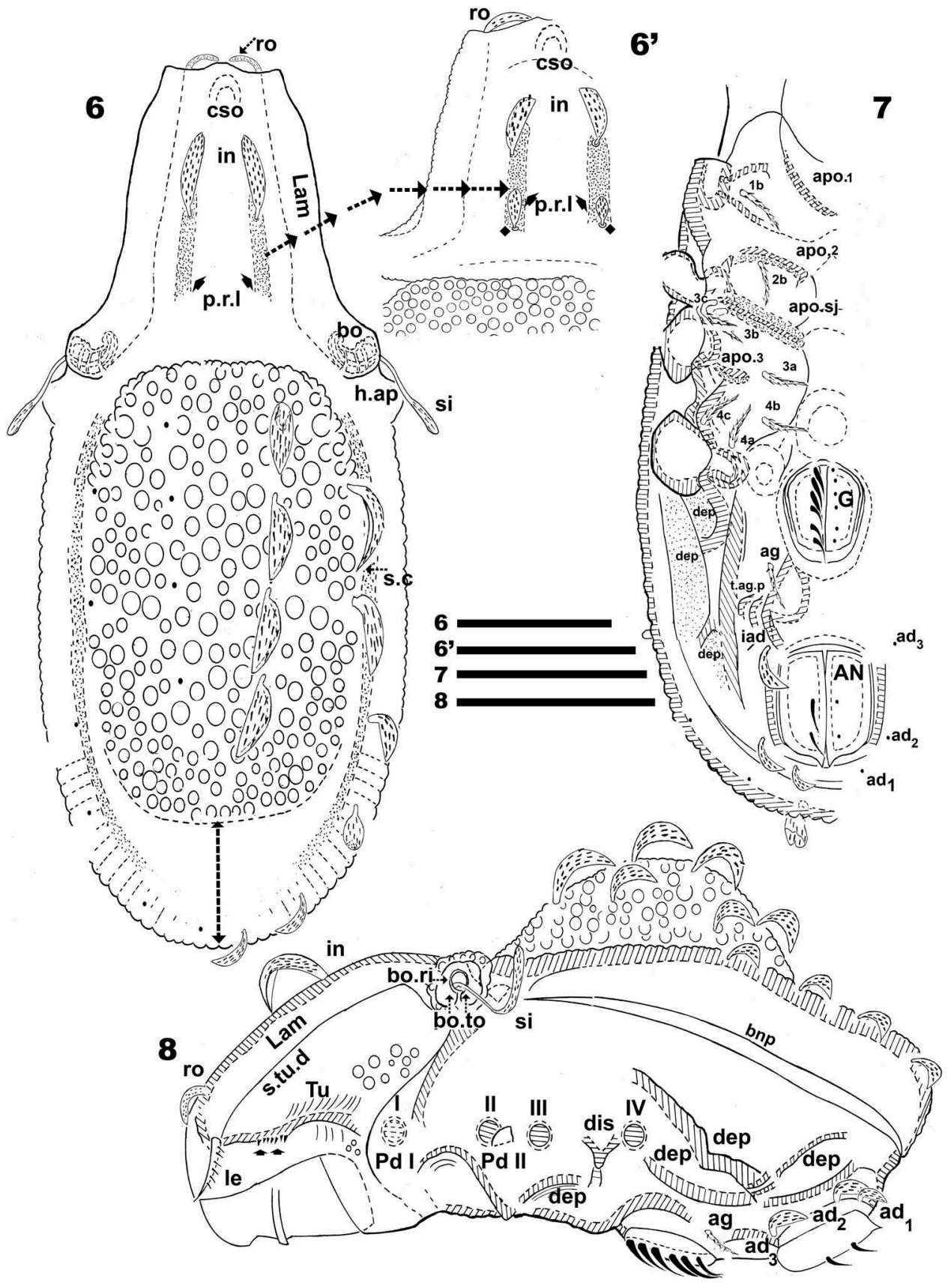

Figure 6-8. Phyllocarabodes costaricensis sp. nov. Adult female, Optical observations. 6. dorsal view; 6'. detail prodorsal area; 7. ventral view; 8. Lateral view. Abbreviations: see section on "Material and methods". Scale bars: $6,6^{\prime}=100 \mu \mathrm{m} ; 7=130 \mu \mathrm{m} ; 8=120 \mu \mathrm{m}$.

(Figures 15 and 17), lamellar zone, tutorial zone, pedotecta I, femur I-IV (Figure 27); punctate: between elevated notogastral zone and marginal notogastral zone (Figures 1 and 6 indicated by - -); granulate: epimeral zone (Figures 32, 33 and 39).

Setation. Large variation: in setae: salix leaf-shaped with small barbules and raised central region, length 36-44 $\mu \mathrm{m}$, width $10 \mu \mathrm{m}(\mathrm{n}=6)$ (Figures 2 and 9). Notogastral setae, length 34-40 $\mu \mathrm{m}$, width $14 \mu \mathrm{m}$ (Figures 1, 3 and 9); adanal $a d_{1}, a d_{2}$, $a_{3}$, length 28-34 $\mu \mathrm{m}$, width $7 \mu \mathrm{m}$ (Figures 28 and 32): ovoid leaf-shaped, central zone elevated with barbules and slightly rugous margin. Setae ro: elongate leaf-shaped, central zone slightly elevated with small barbules and rugous margin, length 55-61 $\mu \mathrm{m}$, width $8 \mu \mathrm{m}$ (Figures 1, 5 and 9). Setae le: long phylliform with small dentitions, length 54.5-60.5 $\mu \mathrm{m}$, width $2.5 \mu \mathrm{m}$ (Figure 4). Anterior three pairs of ge setae: large, broad, curving setiform. Three posterior pairs of ge setae: setiform with longitudinal ribs, length 18-24 $\mu \mathrm{m}$, width $2 \mu \mathrm{m}$ (Figures 37, 44 and 45) (see ventral region). Subcapitular $h$ setae: leaf-shaped with small barbules, length 23-29 $\mu \mathrm{m}$, width 4-5 $\mu \mathrm{m}$ (Figures 24 and 25). Subcapitular $m$ setae: slightly inflated setiform (Figures 40). Epimeral setae: elongate leafshaped, with barbs (Figures 33). Anal setae spiniform (Figure 34). Subcapitular a setae slightly flabellate (Figure 42). Setae ag setiform with longitudinal ribs and marginal dentition (Figure 29).

Prodorsum. Prodorsum trapezoidal (dorsal view) (Figures 1 and 6); triangular, rounded apex in frontal view (Figure 9); polyhedral in lateral view (Figure 27).Elevated interlamellar process (e.i.p) flat, slightly convex (Figures 1, 9 and 27); posterior notogastral depression absent (Figures 1 and 6). Conspicuous prodorsal longitudinal ridge (p.l.r) (Figures 1 and $\left.6,6^{\prime}, 9,15\right)$ originating near posterior transversal furrow (t.p.p.f) (Figure 1); in setae inserted on p.l.r. Prodorsal longitudinal ridge exceeding level of in setal insertions, but not extending to level of ro setal insertion (Figures 1 and 9); forward and slightly medially directed curved in setae 

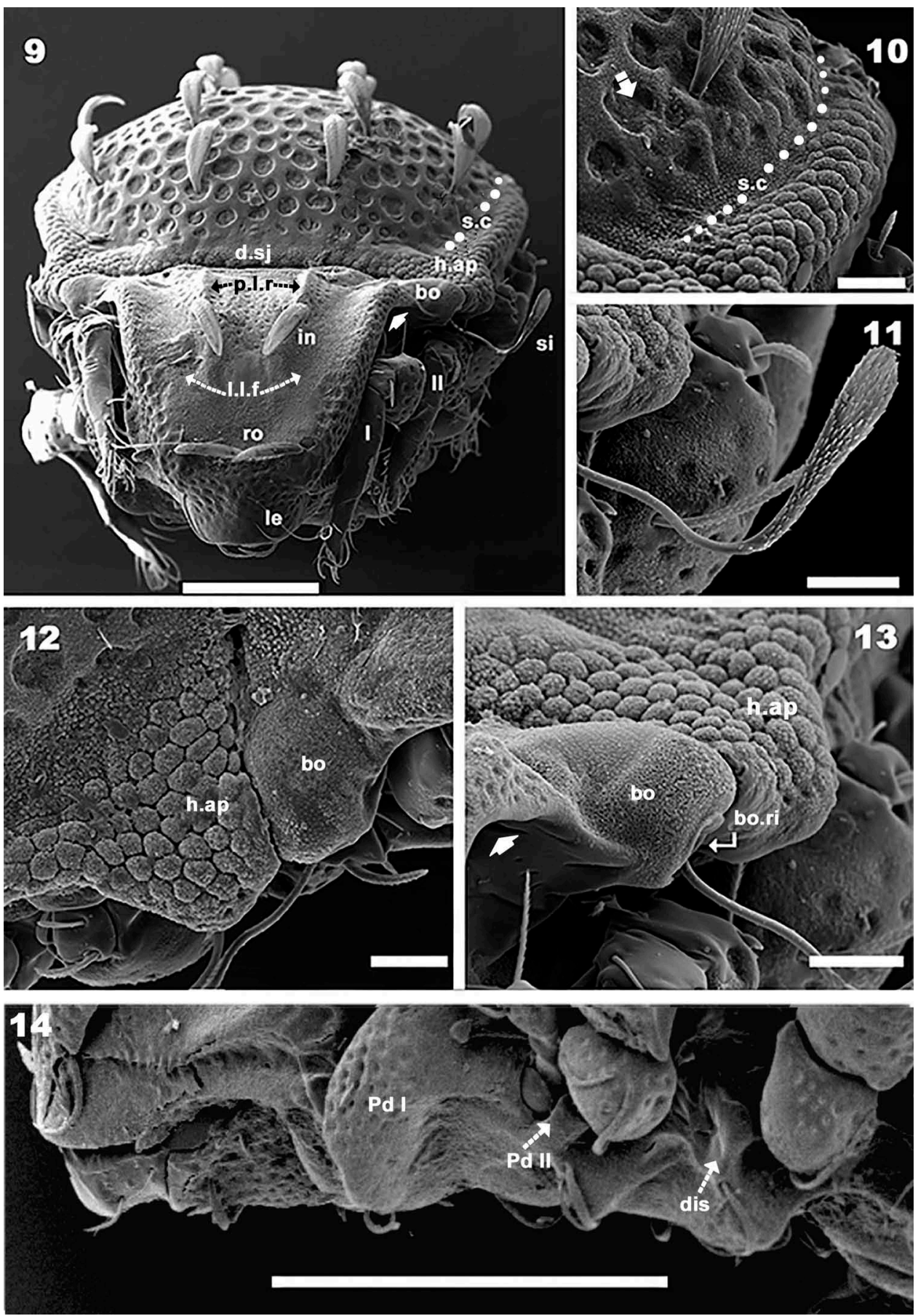

Figure 9-14. Phyllocarabodes costaricensis sp. nov. Adult female, SEM observations. 9. frontal view; 10. lateral view, posterolateral notogastral zone; 11. sensillus, lateral view; 12. humeral apophysis; 13. bothridium anterior lateral view, bothridial ring zone; 14. lateral zone, Pd I, Pd II, dis. Abbreviations: see section on "Material and methods". Scale bars: $14=200 \mu \mathrm{m} ; 9=100 \mu \mathrm{m} ; 10,11,12,13=20 \mu \mathrm{m}$.

(Figures 1, 6 and 9); ro setae directed anteriorly and slightly medially, apical tips overlapping (Figures 1, 9 and 21).

Sensillus (si) spatulate (Figure 11). Bothridial opening directed ventrally (Figures 13, 27, 31, 35 and 38), well defined, smooth bothridial ring (bo.ri), situated internally to bothridial opening with prominent bothridial tooth (bo.to) (Figures 8 and 35); bo. to easily distinguishable. Rostral margin rounded, protruding, resembling a duck bill, slightly rectilinear (Figure 9).

Notogaster. In dorsal view anterior notogaster rectangular, with lateral protruding humeral tubercle (h.ap); posterior oval (Figure 1); in lateral view convex (Figures 8 and 27). Anterior and posterior depressions absent (Figure 1); d.sj large, more or less rectilinear, clearly delimited. Circumgastric furrow (s.c) trajectory not extending to posterior; central elevated notogastral zone visible in Figures 1, 9, 10 and 27 (indicated with white dots, also indicating different diameters. Dots small in zone where s.c not visible or very shallow). Central notogastral zone "light bulbshaped", convex with foveate microsculpture (see "Discussion" section), starting slightly posterior to $d . s j$ and ending close to marginal setae; flattened zone between end point of foveate microsculpture and marginal zone (indicated in Figures 1 and 6 by - .

Ten pairs of ovoid leaf-shaped setae, described above (Figures 1, 3, 6, 9 and 27). Polyhedral shaped humeral apophysis (h.ap), easily observed; anterior zone overlapping posterior bothridial zone (Figures 1, 9, 12 and 13) (See discussion); completely different ornamentations in bo and h.p zones (Figures 12 and 13); posterior h.ap. zone concave (Figure18 indicated by -), 

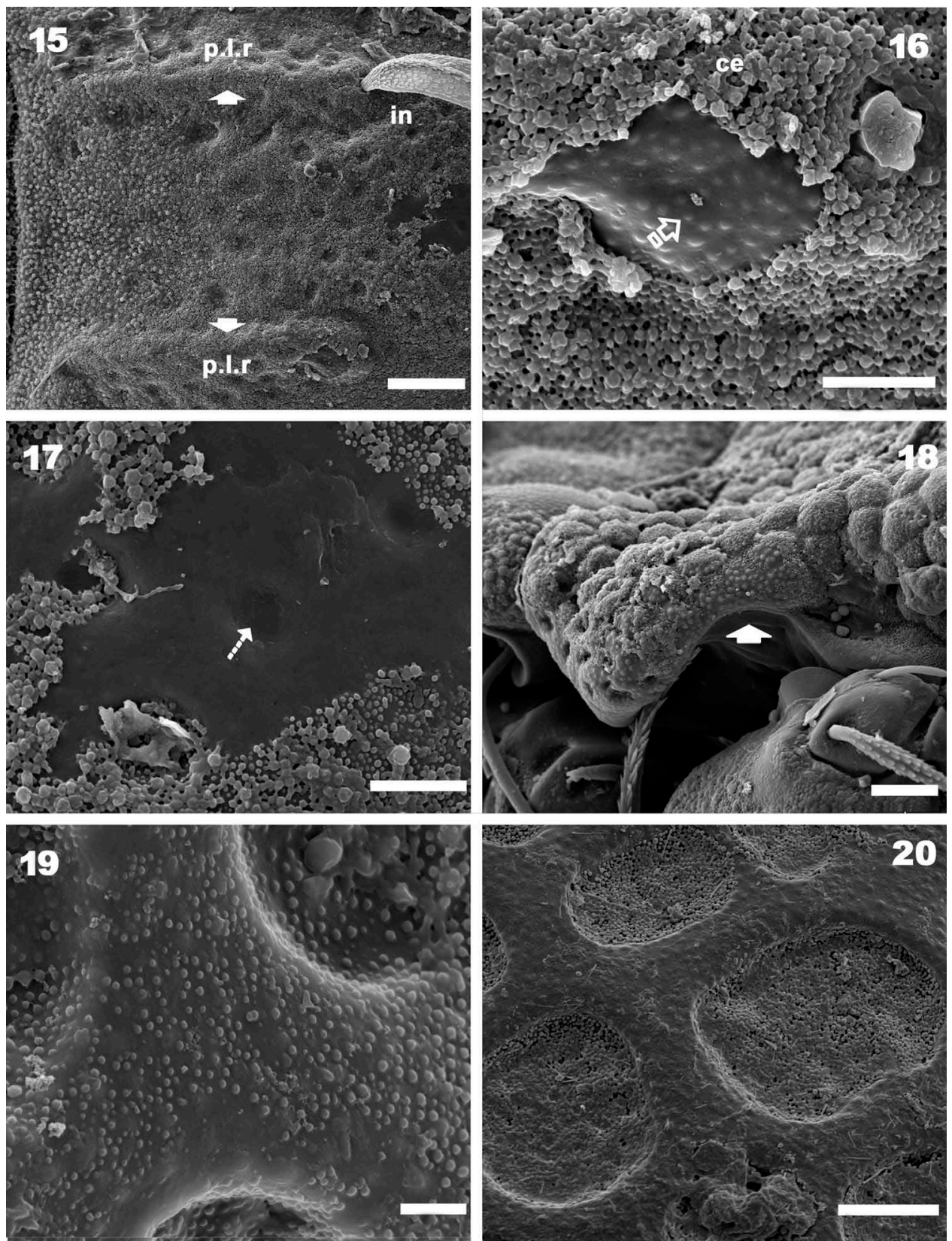

Figure 15-20. Phyllocarabodes costaricensis sp. nov. Adult female, SEM observations. 15. prodorsum: interlamellar zone with p.I.r; 16. prodorsum: cerotegumental layer and cuticular microsculpture; 17. prodorsum: detail of cuticular microsculpture; 18. humeral apophysis, posterior view; 19. notogastral microsculpture; 20. notogastral microsculpture. Abbreviations: see section on "Material and methods". Scale bar: $15=20 \mu \mathrm{m} ; 18,20=10 \mu \mathrm{m} ; 16,17=5 \mu \mathrm{m} ; 19=2 \mu \mathrm{m}$.

adapted to accomodate leg III during leg folding and coaptation (Fernandez et al. 2013a).

Lateral region. Clearly discernible curved lamellae (lam); le setae curving (Figure 4), inserted on apical lamellar zone (Figures 21 and 22); h.ap concave in posterior view (Figure 18). Tutorium (tu): large curving lamina, margin undulate, cuticle foveate; with aligned dentition (Figures 21 and 22, indicated by $\square, 27$ ). Supratutorial depression (s.tu.d) well developed; two large pocket depressions between $T u$ and $P d$ l; large depression (a.tu.d) ventral to tutorial dentition; deep p.tu.d (Figures 21 and 22). $P d$ I: large extended lamina; $P d$ II: small rectangular lamina (Figures 8, 14 and 27); discidium (dis) hardly discernible, small triangular to rounded apex (Figures 8 and 14).

Bothridia rounded, curling to resemble a mouse ear; bothridial opening directing downwards (Figures 13, 31, 35 and 38); bothridial ring (bo.ri) smooth externally and internally (Figures 8, 31, 35 and 38), incomplete; with bothridial tooth (Figures 8, 31, 35 and 38). Si cylindrical, arching dorsally (Figures 9 and 11), with short barbs (Figure 11).
Frontal view. Figures 9, 10, 13 and 18 facilitate understanding of the shape and disposition of prodorsal and notogastral topography, as well as: in setae, ro setae, lam, le setae, Tu, Pd l, h.ap shapes and prodorsal and notogastral setal disposition.

Slightly elevated e.i.p with flattened surface, with specific microsculpture (Figure 9); I.I.f small depressed area; foveate zones and more or less smooth cuticular surfaces easily observed (Figures 9 and 10); bo, h.ap, and concave marginal zone (Figure 18 indicated by - ) situated anterior to bothridial area; the bo.ri clearly discernible (Figures 13, 31, 35 and 38). The s.c originates in posterior zone of h.ap, running externally to elevated notogastral zone (Figures 1, 9, 10 and 27). Trajectory of s.c. incomplete, disappearing or becoming flattened on posterior elevated notogastral zone (Figures 1, 9, 10 and 27 indicated by line of large white dots). Colliculate and granulate microsculpture of h.p, s.c, and bo clearly differentiated (Figures 9, 10, 12 and 13); foveate microsculpture of elevated central notogastral zone clearly visible (Figure 10 indicated by 仓ิ).

Ventral region. Subcapitular setae $h, m, a$ differing in shape (See setation); $h$ setae directing paraxially (Figures 24 and 43 ); $m$ setae 

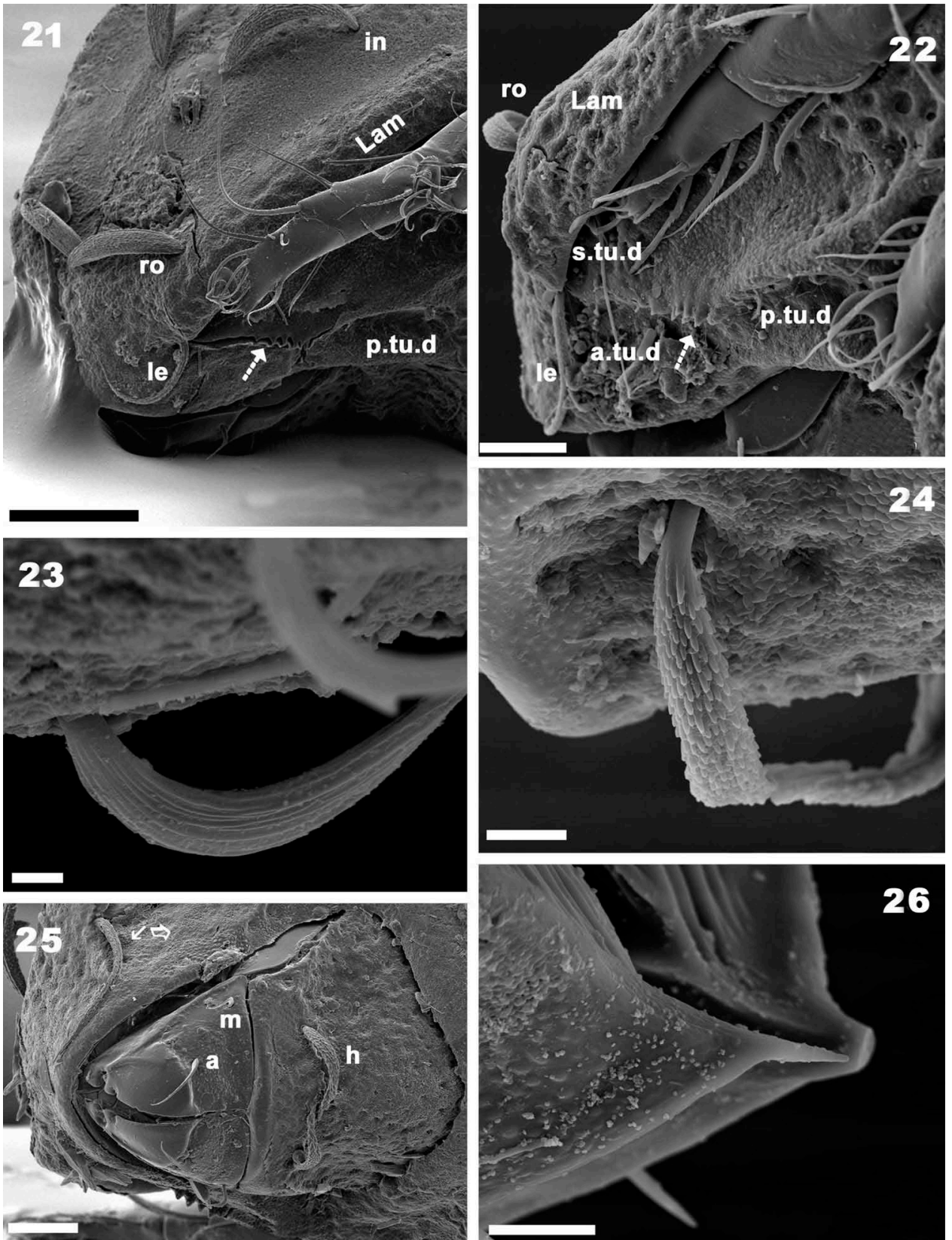

Figure 21-26. Phyllocarabodes costaricensis sp. Nov. Adult female, SEM observations. 21. prodorsum anterolateral view; 22. prodorsal anterior zone, lateral view; 23. genital seta; 24. subcapitular $h$ setae. 25. subcapitulum lateral view; 26. posterior anal apical zone. Abbreviations: see section on "Material and methods". Scale bar: $21=50 \mu \mathrm{m} ; 25=25 \mu \mathrm{m} ; 22=20 \mu \mathrm{m} ; 24,26=5 \mu \mathrm{m} ; 23=2 \mu \mathrm{m}$.

directing laterally (Figure 40); a setae directing anteriorly (Figure 42). Epimera slightly elevated, delimited by shallow furrow (bo.1, bo.2, bo.sj, bo.3). Epimera 3 and 4 fused (Figures 7 and 39); medial epimeral zone with longitudinal depression (Figure 39); apo.1, apo.2, apo.sj and apo.3 clearly discernible (Figure 7).

Epimeral setae (Figures 30 and 33); setal formulae: 1-1-3-3; all setae same shape and length (Figures 27 and 36); 3b, 3c closely adjacent, more or less parallel (Figure 33). Genital plate small in relation to anal plate (Figure 39). Six pairs of genital setae, differing in shape (See setation) (Figure 44); three anterior pairs are large, wide and curving (Figure 45); three posterior pairs longer, more or less flabellate (Figure 37). Discidum small, hardly discernible. Clearly observed depression surrounding genital opening; a.g.f clearly observed, extending from anterior to genital plate to posterior epimeral margin (Figure 39, trajectory indicated by large white dots). Ag setae (Figure 29), ad setae (Figure 28), situated some distance apart (Figure 39), aggenital setae situated posterior to genital opening, in shallow depressed area, directed posteriorly and paraxially; posterior aggenital insertion on series of promontories laterally and paraxially to these setae (Figure 39 indicated by $\nearrow$ ). Between genital and anal plate, shallow, polyhedral depression (Figure 39 indicated by $\$$ ). Three pairs of paraxially directing adanal setae: $a d_{3}-a d_{1}$ (Figures 28 and 32). Anal plate polyhedral, sharply tipped (Figures 26 and 39). Two pairs of anal setae (Figure 39). Lyrifissure iad situated laterally at level $\mathrm{ad}_{3}$ setae (Figure 7). Several depressions (dep) clearly visible (Figures 27 and 39).

Legs (Figures 35-38). All legs monodactyle. Setal formulae I (1-32-4-16-1) (1-2-2); II (1-2-3-3-17-1) (1-1-2); III (2-3-1-2-14-1) (1-1-0); IV (1-2-2-2-13-1) (0-1-0).

\section{Remarks}

The following characteristics permit easy differentiation of $P h$. Costaricensis from other congeners: variation in cuticular microsculpture; shape and disposition of prodorsal and notogastral setation; disposition and shape of bo and h.ap; presence of 

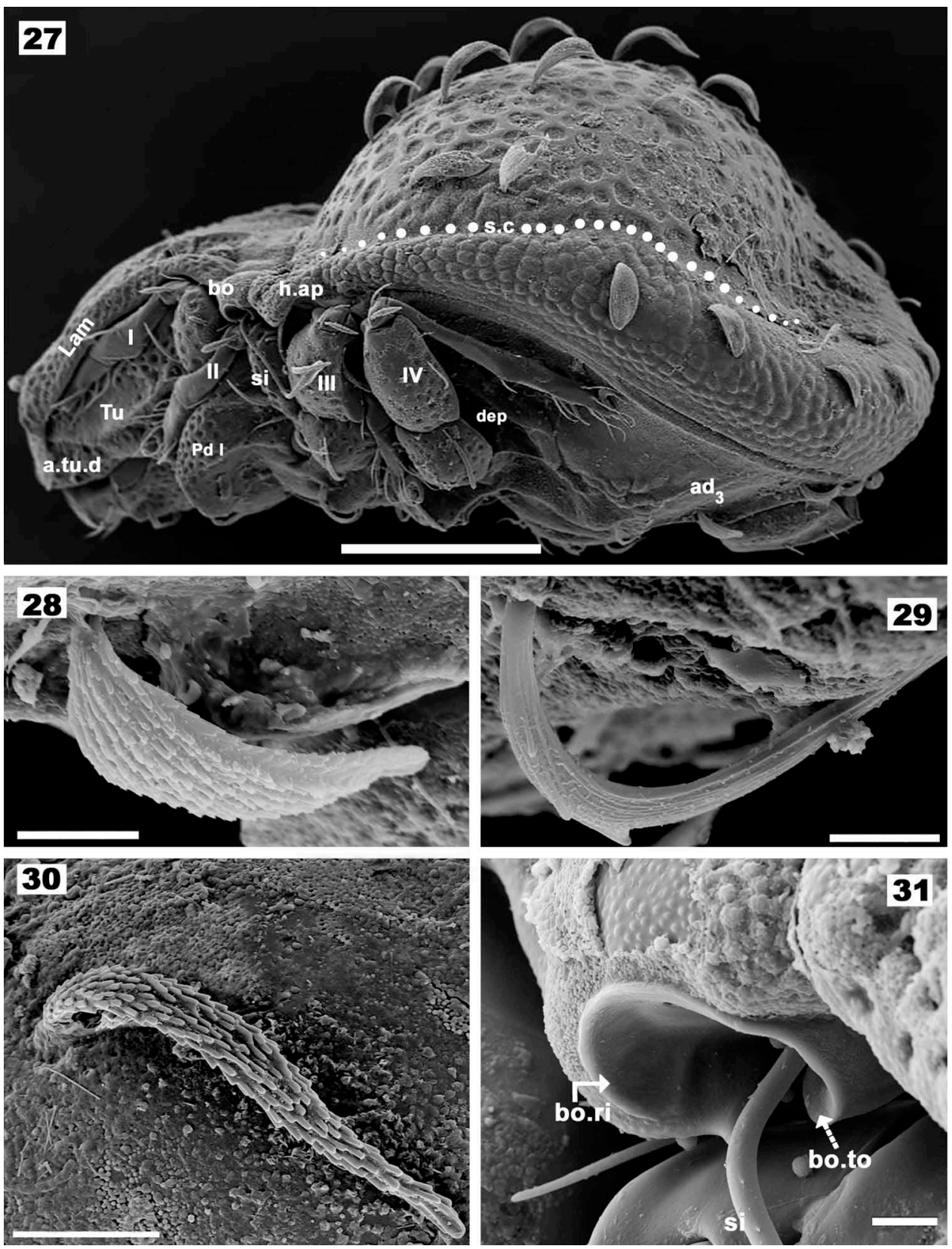

Figure 27-31. Phyllocarabodes costaricensis sp. nov. Adult female, SEM observations. 27. lateral view; 28. adanal setae; 29. aggenital setae, detail; 30. epimeral seta $2 a ; 31$. bothridium and bothridial ring. Abbreviations: see section on "Material and methods". Scale bar: $27=100 \mu \mathrm{m} ; 28,30=10 \mu \mathrm{m} ; 29,31=5 \mu \mathrm{m}$.

bothridial ring and bothridial tooth; epimeral setal formula 1-1-33 ; setae $3 b$ and $3 c$ situated closely adjacent.

Interesting anomalies are observed on the prodorsal longitudinal ridge (p.l.r), where in setae are usually found. In this instance, two pairs of in setae are situated on the ridge; one in normal position and behind them, another smaller pair (Figure 6').

\section{New taxon description}

Zimbabweae kenyaensis sp. nov.

(Figures 46-71, Table 1)

\section{Etymology}

The specific epithet is derived from Kenya, country of origin of type material.

\section{Material examined}

Holotype: Female "KEN 77-63. Nakuru distr. Mau escarpment, près de Enangipen. Tamisage dans la forêt alt. $2700 \mathrm{~m}$. 6.XI. 1977. LEG V. Mahnert \& J.L. Perret"; material deposited in the Collection of tNHMG, Switzerland; preserved in $70 \%$ ethanol.
Paratype Two adult females, same locality and date as Holotype; deposited in Collection of NHMG; preserved in $70 \%$ ethanol. Material studied with SEM: three specimens, not deposited.

\section{Diagnosis (adult female)}

Microsculpture. Colliculate: posterior notogastral zone, between s.c and $p_{1}, p_{2}, p_{3}, h_{3}$. Pustulated: bo, ventral and lateral depressions, subcapitulum, near setae $a, m, h ; T u$, s.tu.d, p.tu.d, a.tu.d. Rugose: e.i.p, surrounding in setal insertion; notogaster near $c_{3}$ setae; lamellae near le setae; epimera, genital plate. Foveate: e.i.p zone promontories; posterior notogastral zone; $p r m d p$ setae and zone between prm $d p$, prm $d m$ setae and prm $h_{1}, p r m h_{2}, p r m ~ I p$ setae; apical zone of lamellae, subcapitulum, anterior to insertion $h$ setae. Punctate: prodorsum near in setae; notogastral zone between foveae; externally to s.c. Smooth: bo.ri, bo.to.

Setation. Epimeral, aggenital, genital setae simple; in setae leafshaped, rugous, with small barbs and central longitudinal furrow; ro, notogastral setae simple, small asperities; $h, m$, a setae simple, 


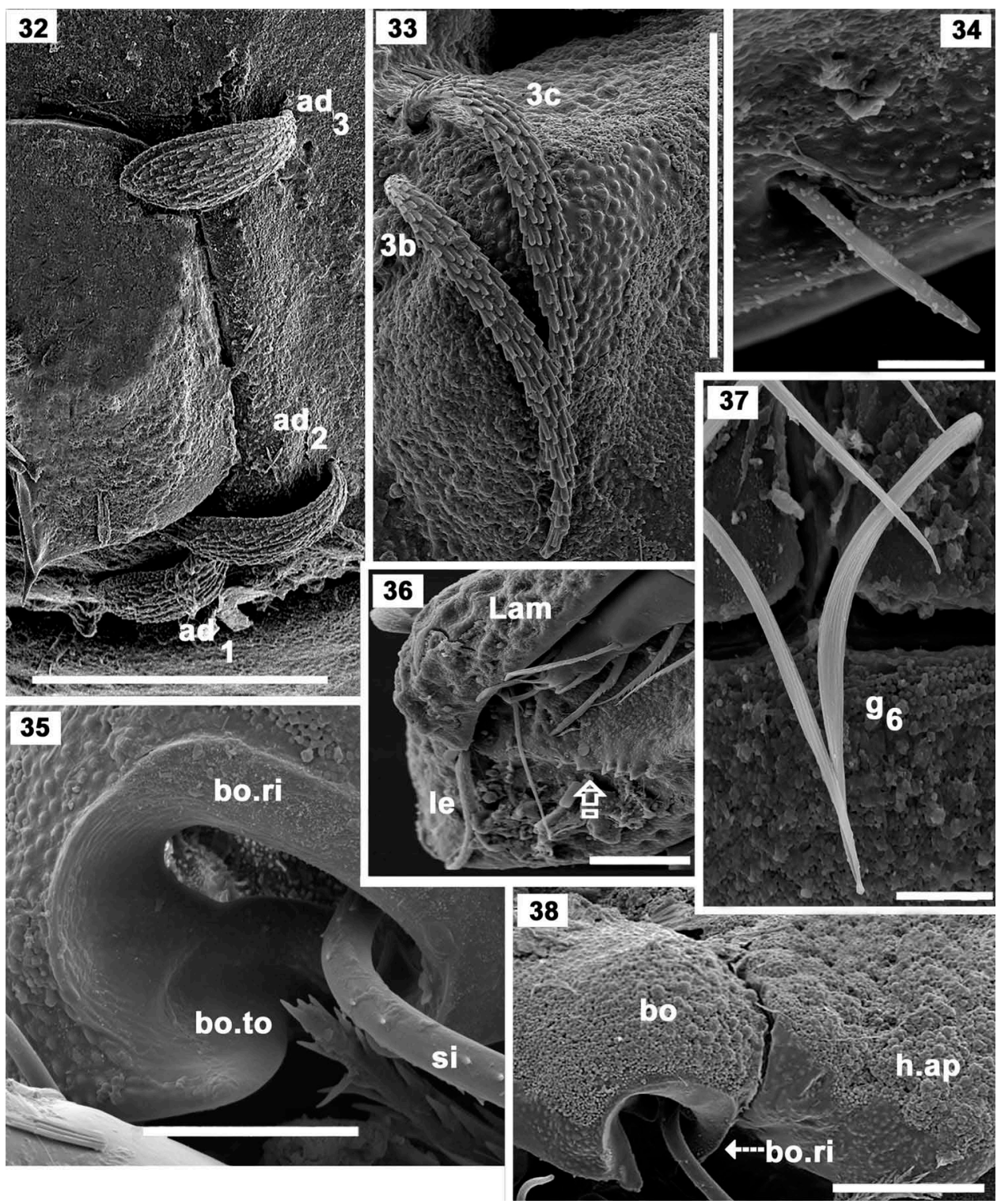

Figure 32-38. Phyllocarabodes costaricensis sp. nov. Adult female, SEM observations. 32. anal zone with adanal setae; 33. epimeral setae 3b, 3c; 34. anal setae. 35. bothridium, lateral view; 36. prodorsum, apical zone; 37. genital setae, $g_{6} ; 38$. bothridium dorsolateral view. Abbreviations: see section on "Material and methods". Scale bar: $32=50 \mu \mathrm{m} ; 38,36=20 \mu \mathrm{m} ; 33,35=10 \mu \mathrm{m} ; 34,37=5 \mu \mathrm{m}$.

lateral vein; le setae wide, leaf-shaped, dentate margin, with small central teeth; an setae small spur.

Prodorsum. Rectangular between d.sj and level of promontories, posterior to elevated interlamellar process; anterior more or less trapezoidal, with semicircular margins. Elevated interlamellar process with irregular promontories and depressions, divided into two lateral zones by flat medial depression. Three protuberances observed: one sigmoid lateral protuberance, situated internally to in setae insertion level; second, rounded to irregular protuberance, situated lateral to in setal insertion; third protuberance, rounded in dorsal view, situated marginally, lateral to the second promontory. Relatively deep shallow lamellar furrow; ovoid CSO between ro setae. Posterior prodorsal depression divided into two (anterior and posterior) by translamellae. Lamellae running dorsolaterally, with large, slightly curving translamella. Lamellar tips connected to cuticular extension bar. Cylindrical, barbed sensillus, curving dorsally. Bothridial ring and bothridial tooth smooth.

Notogaster. Anterior zone trapezoidal; medial to posterior zone ovoid; rectilinear, narrow d.sj; n.a.d large, extending posteriorly, exceeding level of $d a$, la setal insertions; elevated Y-shaped cuticular ridge dividing n.a.d into two longitudinal zones. Y-shaped structure extending anteriorly almost to d.sj; two superior Y-branches posteriorly exceeding da setal insertion; depression between branches of $Y$ in central superior zone. Fifteen pairs of setae: $c_{1}$, $c_{2}, c_{3}, d a, d m, d p, l a, I m, I p, h_{1}, h_{2}, h_{3}$. All setae except $p_{1}, p_{2}, p_{3}$ inserted on promontories. Promontories prm da and prm la, prm Im setae connected by oblique promontory. Circumgastric depression between $I a, I m, I p, h_{2}, h_{1}$ and $h_{3}, p_{3}, p_{2}, p_{1}$ setae; trajectory of circumgastric depression changing to sigmoid slightly anterior to $h_{3}$ setae. Projecting humeral apophysis with oblique depression; short transverse furrow anterior and posterior to $c_{3}$ setae.

Ventral region: slightly elevated epimera; setae on rounded promontories; longitudinal furrow on paraxial zone of epimera 1-3; epimeral chaetotaxy 3-1-3-3. Epimeral setae 1a, 2a, 3a, 4a small. Discidium well discernible; a.g.f present, connected to lateral genital depression by tube-shaped structure; four pairs of long genital setae; ag setae posterior to external genital opening; situated laterally and close to $a d_{3}$; setae $a g$ and $a d_{3}, a d_{2}, a d_{1}$ differ in shape; polyhedral, sharply tipped anal plate; two pairs of anal setae. Polyhedral depressions situated laterally to genital and anal zones and between openings.

\section{Description}

Measurements. SEM $620 \mu \mathrm{m}(605-642) \times 315 \mu \mathrm{m}(310-330)$ $(n=6)$. Light microscopy: $630 \mu \mathrm{m}(615-645) \times 322 \mu \mathrm{m}(317-$ 341) $(n=3)$. 

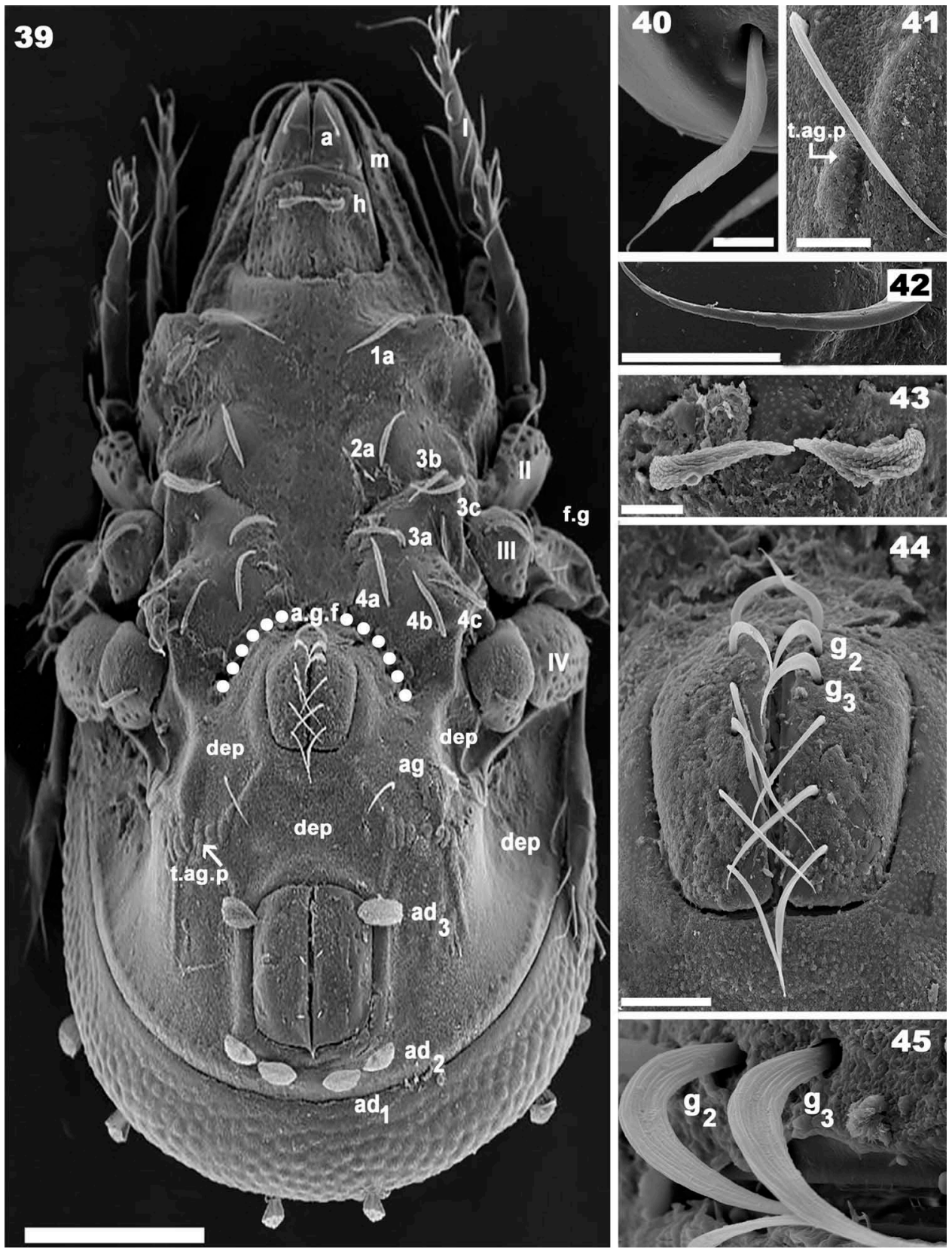

Figure 39-45. Phyllocarabodes costaricensis sp. nov. Adult female, SEM observations. 39. ventral view; 40. subcapitular setae $m$; 41. aggenital setae, general view with transverse cuticular promontories; 42. subcapitular setae $a$; 43. subcapitular setae $h$; $\mathbf{4 4}$. genital plate; 45. detail genital $g 1-g 3$ setae. Abbreviations: see section on "Material and methods". Scale bar: $39=100 \mu \mathrm{m} ; 44=20 \mu \mathrm{m} ; 42-43=10 \mu \mathrm{m} ; 40,41,45=5 \mu \mathrm{m}$.

Shape. Prodorsum polyhedral and notogaster ovoid (Figure 46).

Colour. Specimens without cerotegument, brown to light brown when observed in reflected light.

Cerotegument. Grainy, only present on posterior prodorsal depression (p.p.d $d_{1}$ p.p. $d_{2}$ ) and notogaster, zone of s.c (Figures 51 and 56).

Integument. Microsculpture: colliculate: posterior notogastral zone between s.c and setae $p_{1}, p_{2}, p_{3}, h_{3}$ (Figure 48 indicated by -). Pustulate: bo, h.ap (anterior zone) (Figure 61, indicated by 仓), zone of $\mathrm{ppd}_{2}$ (Figure 51, indicated by $\vartheta$ ), s.tu.d zone (Figure 60), posterior zone Pd I (Figure 60). Rugose: e.i.p surrounding in setae insertions (Figure 46), notogaster near $c_{3}$ (Figure 58), zone ag, ad setae (Figure 71), surrounding in setae (Figure 64). Foveate: (Figures 48 and 66) fovea rounded to polyhedral in shape: posterior zone, promontories $d p, h_{1}$ setal promontories extending to s.c (Figure 48), subcapitulum (Figure 70), anterior zone to ro setae (Figure 47 indicated by 1 ). Smooth prodorsum (Figure 47), anterior notogastral zone (Figures 46 and 47), ventral zone (Figure 68).

Setation. Notogastral setae (Figures 52, 60 and 67), ro (Figure 53), epimeral (Figure 69), ag, ad (Figure 71): simple with very fine barbs; genital setae simple (Figure 68); in setae leaf-shaped, rugous, with small asperities and central longitudinal furrow (Figure 64); le setae wide, leaf-shaped, margin dentate, with small central teeth (Figure 54); anal setae spiniform (Figure 68).

Prodorsum. Dorsal view: generally polyhedral in shape, zone B (indicated by dotted transverse line in Figure 46), rectangular between d.sj and level of promontories posterior to e.i.p (p.p.p); zone A (indicated in Figure 46 by dotted transverse line), more or less trapezoidal with semicircular margins. Frontal view (Figure 47), triangular with irregular semicircular margins; d.sj concave (Figure 46); elevated e.i.p with irregular promontories and depressions, divided into two lateral zones by concave medial depression (Figures 46, 47 and 51 indicated by - ). 

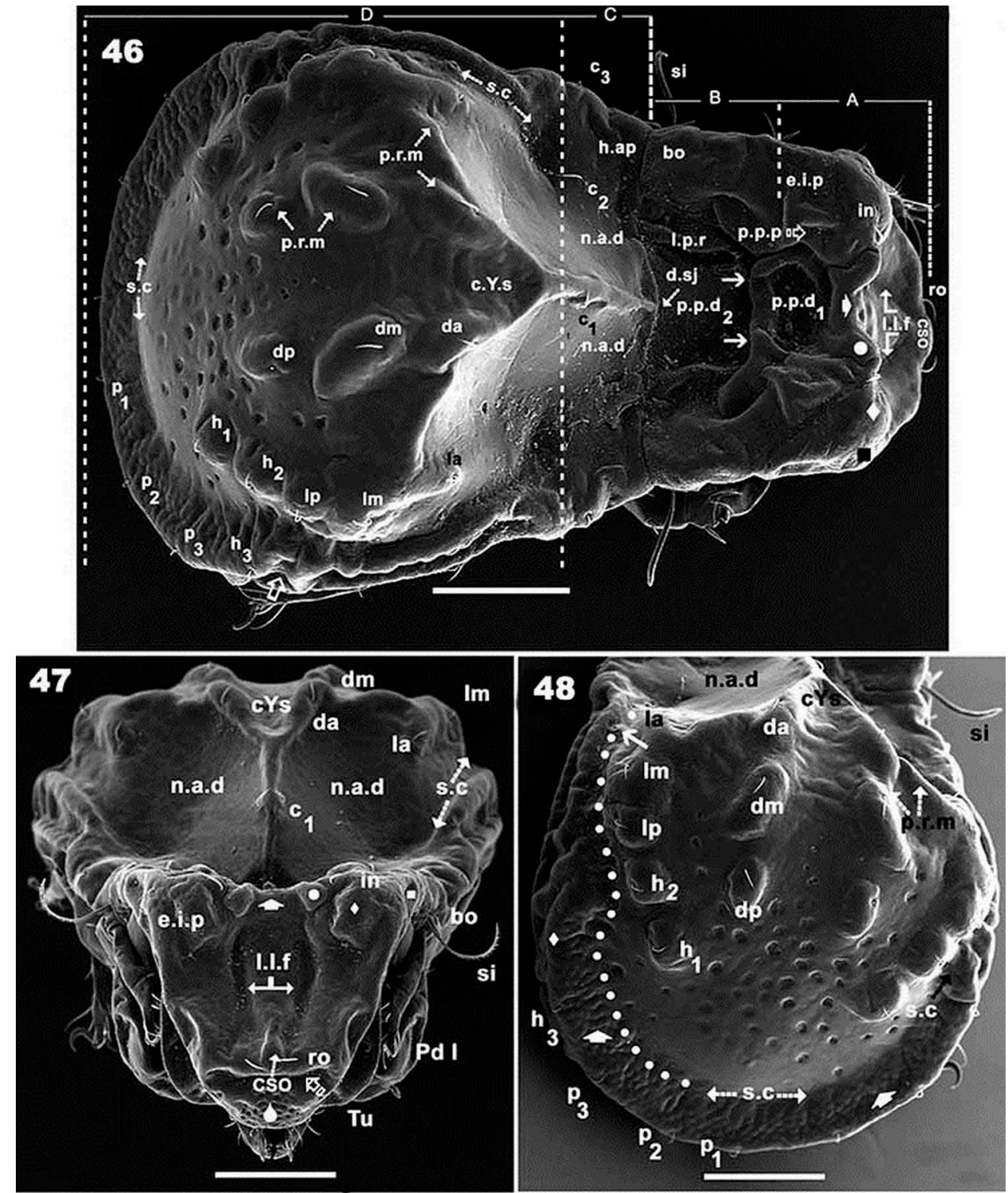

Figure 46-48. Zimbabweae kenyaensis sp. nov. Adult female, SEM observations. 46. dorsal view; 47. frontal view; 48. posterior dorsal view. Abbreviations: see section on "Material and methods". Scale bar: $46-48=100 \mu \mathrm{m}$.

Table 1. Zimbabweae kenyaensis sp. nov.: leg setae and solenidia.

\begin{tabular}{|c|c|c|c|c|c|}
\hline $\begin{array}{l}\text { Leg I } \\
\text { setae } \\
\text { solenidia } \\
\text { Leg II }\end{array}$ & $\begin{array}{l}\text { Femur } \\
d, v\end{array}$ & $\begin{array}{l}\text { Genu } \\
I^{\prime} v \\
\sigma\end{array}$ & $\begin{array}{l}\text { Tibia } \\
d, v \\
\varphi_{1}, \varphi_{2}\end{array}$ & $\begin{array}{l}\text { Tarsus } \\
(f t), \varepsilon_{1}(t c),(i t),(p),(u),(a), s, p v^{\prime} \\
\omega_{1}, \omega_{2}\end{array}$ & $\begin{array}{c}\text { Claw } \\
1\end{array}$ \\
\hline $\begin{array}{l}\text { setae } \\
\text { solenidia } \\
\text { Leg III }\end{array}$ & $d p, d a, l \sigma$ & $\begin{array}{l}(l), v \\
\sigma\end{array}$ & $\begin{array}{l}d,(v) \\
\varphi\end{array}$ & $\begin{array}{l}(p v), s,(a),(u),(p),(i t),(t c),(f t) \\
\omega_{1}, \omega_{2}\end{array}$ & 1 \\
\hline $\begin{array}{l}\text { setae } \\
\text { solenidia } \\
\text { Leg IV }\end{array}$ & $d, l^{\prime}, v$ & $\begin{array}{l}l^{\prime} \\
\sigma\end{array}$ & $\begin{array}{l}l^{\prime}, v \\
\varphi\end{array}$ & $\begin{array}{l}(p v), s,(a),(u),(p),(i t),(t c), f^{\prime} \\
-\end{array}$ & 1 \\
\hline $\begin{array}{l}\text { setae } \\
\text { solenidia }\end{array}$ & $d, v$ & $\begin{array}{l}d, l^{\prime} \\
-\end{array}$ & $\begin{array}{l}l^{\prime}, v \\
\varphi\end{array}$ & $\begin{array}{l}(p v), s,(a),(u),(p),(t c), f^{\prime} \\
-\end{array}$ & 1 \\
\hline
\end{tabular}

Each zone comprising three protuberances. One sigmoid to irregular lateral protuberance (Figures 46 and 47) situated internally to in setae insertion level (Figures 46 and 51). In frontal view (Figure 47 indicated by large white •), these promontories appearing rectangular to polyhedral, separated from in setal insertion by simple furrow. Second protuberance situated lateral to in setal insertion, rounded to irregular in dorsal view (Figures 47 and 51 indicated by $\$$ ); appearing rectangular to polyhedral in frontal view (Figure 47 indicated by $\downarrow$ ), separated from first protuberance by large furrow and in setal insertion. Third promontory, rounded in dorsal view, situated marginally, lateral to the second promontory (Figure 46, indicated by $\mathbf{\square})$, forming rounded "ear-shaped" depressed zone in frontal view (Figure 47, indicated by $\mathbf{0}$ ), On e.i.p, posterior to protuberances, more or less rectangular depressed area p.p.p present, with anterior zone of complicated shape (Figures 46 and 51 indicated by $\hat{y}$, this last figure shows different angles of right and left sides). On anterior zone of e.i. $p$, well defined, deep, curving I.I.f (Figures 47 and 60); ovoid, well defined CSO between ro setae (Figure 47).

Large prodorsal posterior depression behind e.i.p, divided into two by translamella (Figure 46 , indicated by $\uparrow$ ), forming one anterior (p.p. $d_{1}$ ) and one posterior (p.p.d $d_{2}$ ) depression; p.p. $d_{1}$ small, polyhedral to rounded, with well delimited internal ovoid structure (Figure 46); p.p.d $d_{2}$ large, rectangular, with lateral posterior ridge (I.p.r) (Figure 46).

Lam running dorsolaterally (Figure 60); translamella large, slightly curving (Figure 46 $\leftarrow$ ). Curving in setae (Figures 47, 60 and 64) (length 14-18 $\mu \mathrm{m}$ ); inserted anteriorly on e.i.p, directed obliquely (Figures 47, 60 and 64); ro setae (Figures 46, 47 and 53) (length 18-24 $\mu \mathrm{m}$ ), directed anteriorly and paraxially (Figures 46 and 47); lateral le setae situated anterior to lamellae (Figures 54 and 60) (length 23-29 $\mu \mathrm{m}$ ) (broader zone 8-12 $\mu \mathrm{m}$ ). Lamellae terminating in prominent la.ti, tips connected to cuticular extension bar (Figure 54 indicated by - ) (See Lateral region). 
Barbed, cylindrical sensillus (si) (77-83 $\mu \mathrm{m})$, curving dorsally (Figures 55 and 61). Bothridial opening directing ventrally (Figures 60 and 61); smooth, clearly defined bothridial ring (bo. ri), with bo.to (Figures 61 and 62). Furrow running externally to bo.ri (Figure 61 indicated by indicated - ). Rostral margin slightly rounded (Figure 47).

Notogaster. Anterior n.a.d longitudinally divided into two (Figures 46,47 and 50) by anterior extension ridge of $c Y_{s}$, extending close to d.sj. Fifteen pairs of setae: $c_{1}, c_{2}, c_{3}, d a, d m, d p, l a, I m, I p, h_{1}, h_{2}, h_{3}, p_{1}$, $p_{2}, p_{3}$; setae $c_{1}$ length: 13-15 $\mu \mathrm{m}$ (Figure 60); $c_{2}$, $c_{3}$ length: 10-14 $\mu \mathrm{m}$ (Figure 58); setae $d a, d m, d p$ length: 22-28 $\mu \mathrm{m}$ (Figure 67); setae $l a$, Im, Ip length: 20-26 $\mu \mathrm{m}$; setae $h_{1}, h_{2}$ length: 10-13 $\mu \mathrm{m}$; setae $h_{3}, p_{1}$, $p_{2}, p_{3}$ length: $18-19 \mu \mathrm{m}$ (Figure 52 ).

Setae $c_{1}$ situated on anterior extension ridges $(c Y s)$ (Figures 46, 47 and 50 ); $c_{2}$ setae situated on minute promontories (prm) on n.a. $d$ (Figures 46 and 60$) ; c_{3}$ setae inserted on rounded lateral promontories (Figures 58 and 60); da setae situated on elongated promontories, on lateral branch of c.Y.s (Figures 46, 47, 48 and
67); $d m$ setae situated on large elongated promontories (Figures 46,48 and 67); $d p$ setae on small rounded promontories (Figures 46, 48 and 67); la setae situated on elongated promontories with rounded edges, anterior to oblique prm connecting c.Y.s. and Im promontories (Figures 46, 48, 50 and 60); Im, Ip setae situated on contiguous rounded polyhedral promontories; the first large, the second small; promontories separated by transverse furrow (Figures 46,48 and 60$) ; h_{1}, h_{2}$ on individual rounded promontories separated by furrow (Figures 46 and 48 ); $h_{3}$ situated on slightly elevated rounded promontories (Figures 46, 48, 52 and 60). Circumgastric depression originating laterally anterior to la setal insertion level (Figures 46 and 56); s.c deflected by promontories (Figures $46,47,48$ and 65 ) to $h_{3}$ setal insertion level; setae $p_{1}, p_{2}, p_{3}$ aligned, situated behind $h_{3}$ (Figures 46, 48 and 52). Clearly defined s.c (Figures 47 and 50) visible from posterior zone h.ap, and surrounding notogaster (Figures 46,47 and 48 ), between $I a, I m, I p, h_{2}$, $h_{1}$ and $h_{3}, p_{3}, p_{2}, p_{1}$ setae (Figures 46 and 48 ).

Promontories bearing $d a$ and $I m$ setae connected by oblique promontories (Figure 60 indicated by -). Humeral apophysis

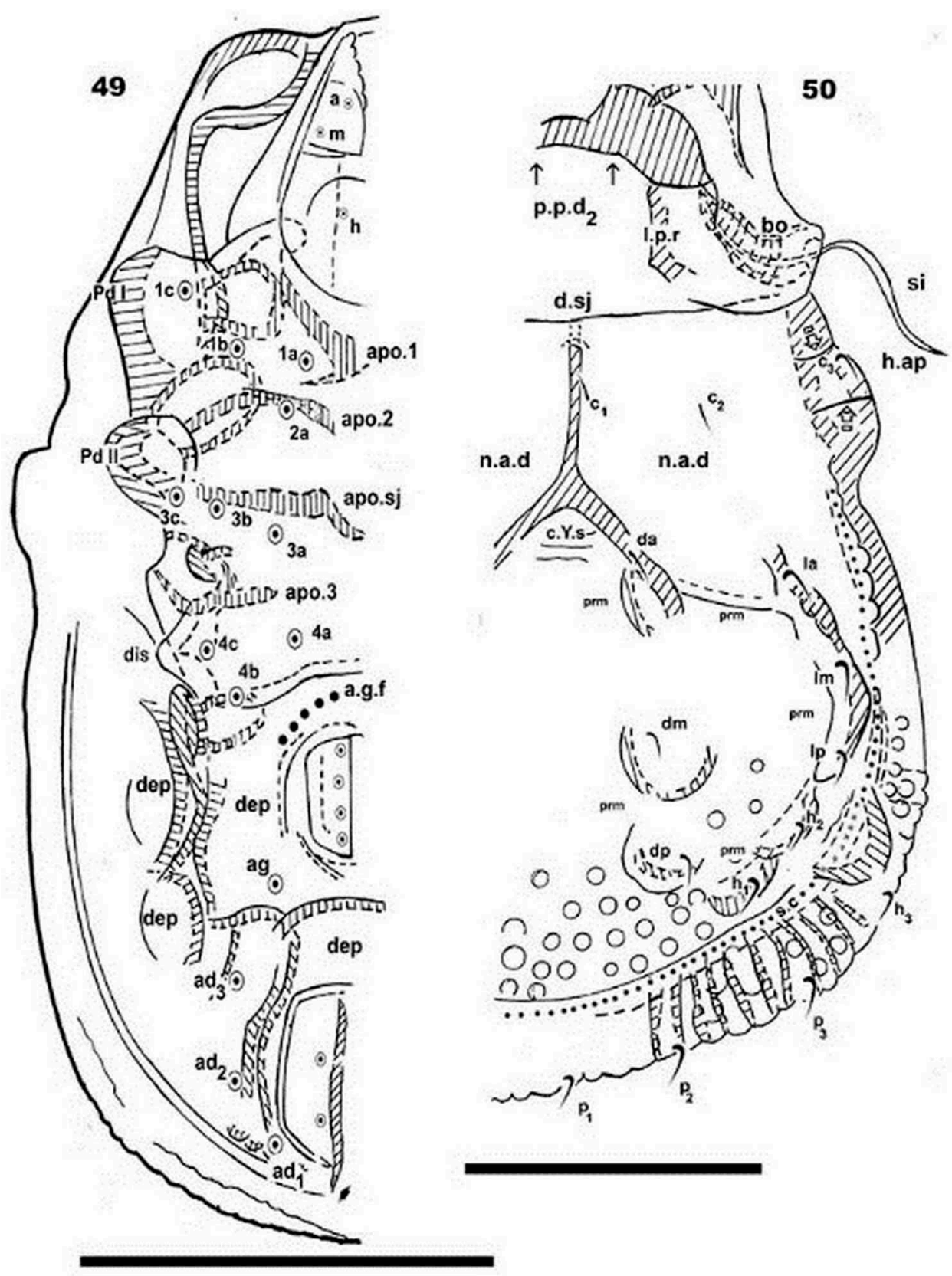

Figure 49-50. Zimbabweae kenyaensis sp. nov. Adult female, optical observations. 49. ventral view; 50. dorsal view. Abbreviations: see section on "Material and methods". Scale bars: $49=270 \mu \mathrm{m} ; 50=230 \mu \mathrm{m}$. 


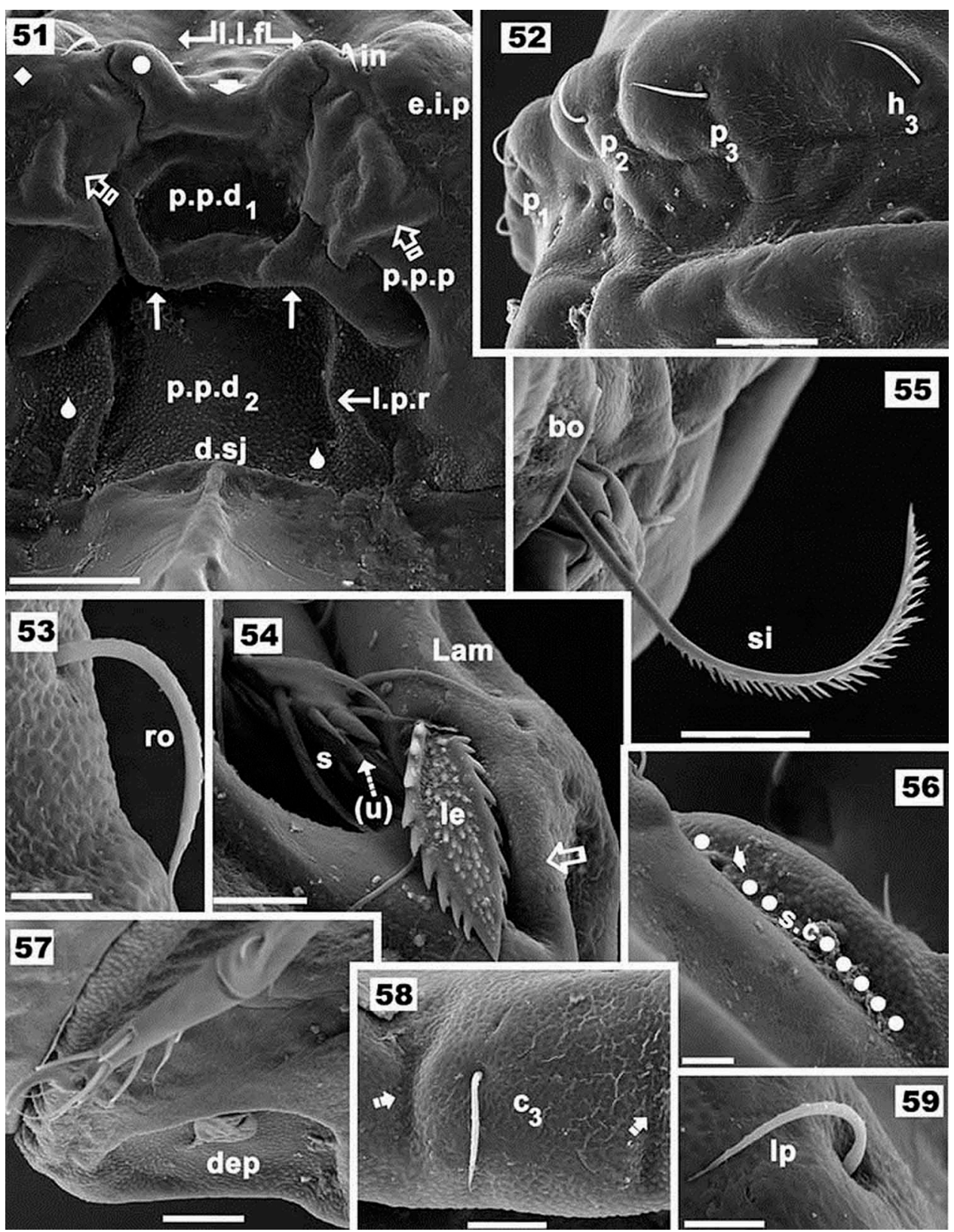

Figure 51-59. Zimbabweae kenyaensis sp. nov. Adult female, SEM observations. 51. prodorsum, anterior region; 52. notogaster, lateral posterior region; 53. rostral setae; 54. lamellar setae; 55. sensillus; 56. notogaster, lateral region; 57. ventral posterior zone depressions; $\mathbf{5 8}$. humeral apophysis, region setae $c_{3} ; \mathbf{5 9}$. notogaster, insertion zone $I p$ setae. Abbreviations: see section on "Material and methods". Scale bars: $51=50 \mu \mathrm{m} ; 52,55,57=20 \mu \mathrm{m} ; 54,56,58=10 \mu \mathrm{m} ; 53$, $59=5 \mu \mathrm{m}$.

(h.ap) long, large projection (Figures 46, 47, 48 and 60); gla situated on c.s slightly posterior to level of la setal insertions (Figure 56 indicated by $\mathbf{c}, 62$ ).

Lateral region. Lamella (lam) easily discernible, with cuticular microsculpture of rounded elongate depressions, large elevations and foveae (Figure 60); bothridial zone pustulate and rugous (Figures 60 and 61); le setal insertion hardly discernible (Figure 60); lamellar tip (la.ti) merged with cuticular surface by cuticular extension bar (Figure 54, indicated by $\mathbf{-}$, 68); Tutorium (Tu) conspicuous, large lamina with curving margin and smooth cuticle, but with some fovea (Figure 60). Two lateral posterior tutorial depressions, p.tu.d $d_{1}$ and p.tu.d $d_{2}$ (Figure 60); supratutorial depression (s.tu.d) (Figure 60) completely concealing leg I during leg folding; one pocket depression (a.tu.d) observed inside s.tu.d (Figure 60); Pd l: large polyhedral lamina (Figure 60) extending externally; triangular in dorsal view, with wide anterior zone and series of four longitudinal depressions (Figure 60, indicated by «..). Pd II: rounded lamina (Figure 60).
Posterior view. Promontories well defined. Trajectory of s.c between prm la, prm Im, prm Ip, prm $h_{1}, p r m h_{2}$ and lateral setal inferior promontories prm $h_{3}$, prm $p_{3,}$ prm $p_{2,}$ prm $p_{1}$, clearly observable (Figure 48 with dotted line). Colliculate cuticular microsculpture between s.c and $p_{1}, p_{2}, p_{3}$ and $h_{3}$ seta clearly discernible, with a prominent extension in posterior zone (Figure 48 indicated by $\checkmark)$. Foveate microsculpture and rounded cavities (Figures 48 and 66) reaching s.c at $d m$, Ip setal promontory level.

Ventral region. Complex epimeral system with raised and depressed areas (Figure 68 indicated by $\$$ ); epimeral setae observed on rounded promontories; epimera 3 and 4 clearly discernible, unfused. Epimeral chaetotaxy 3-1-3-3. Epimeral setae 2a, small (Figure 68); dis small, easily observed (Figure 68); a.g.f clearly visible, situated anterior to genital plate (Figure 60 indicated by large white dot); a.g.f connected to genital lateral depression by tube-shaped structure (Figure 60 indicated by $\hat{\mathrm{r}}$ ).

Genital plate ovoid; four pairs of genital setae arranged in simple line; ag setae situated at level of genital plate tip, lateral 


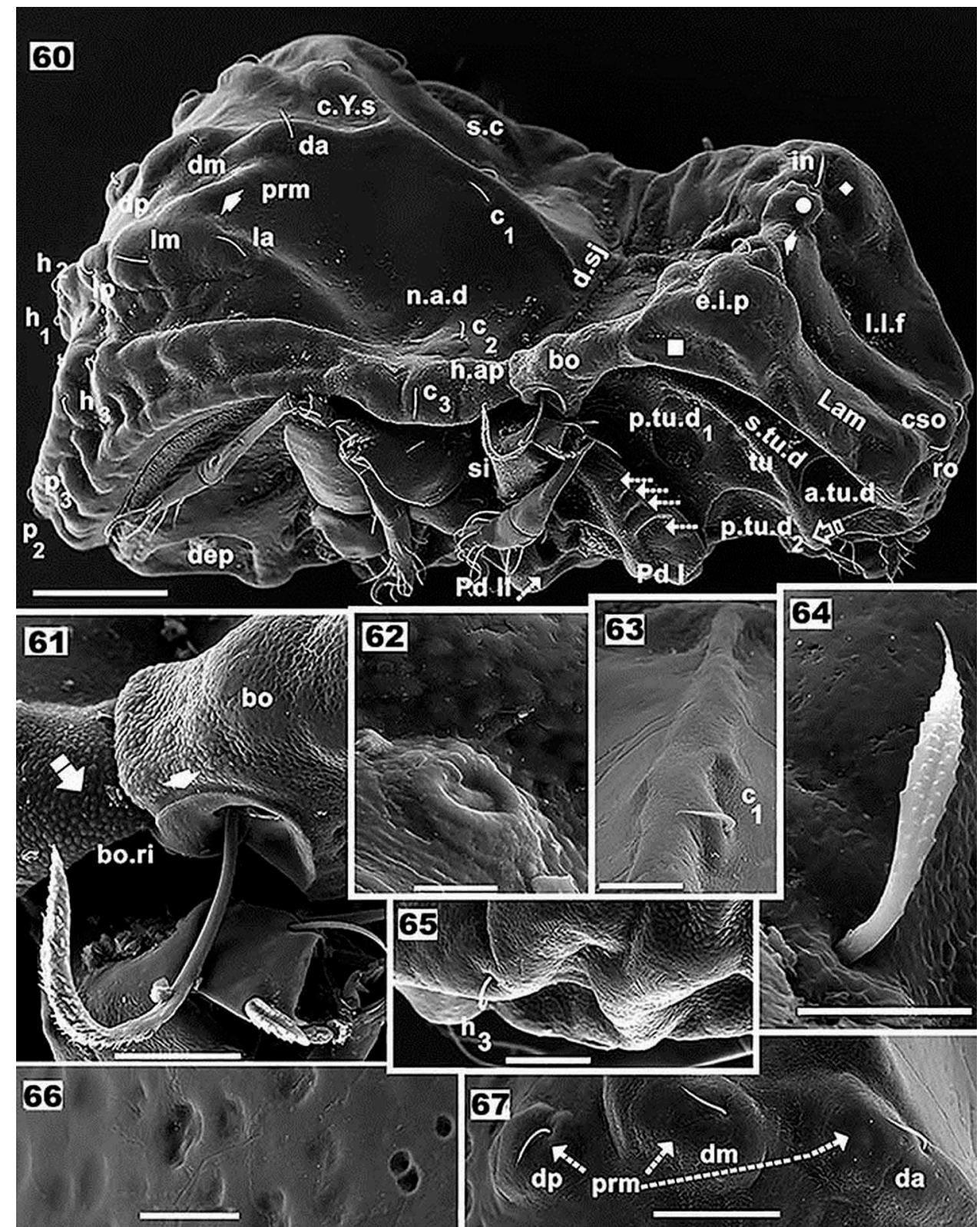

Figure 60-67. Zimbabweae kenyaensis sp. nov. Adult female, SEM observations. 60. lateral view; 61. bothidium and sensillus; 62 . notogastral gla; 63 notogaster, zone of $c_{1}$ setal insertions, lateral view; 64. interlamellar setae; 65. notogaster, lateral region; 66. cuticular microsculpture; 67. zone of setal promontories, setae $d a, d m, d p$. Abbreviations: see section on "Material and methods". Scale bar: $60=100 \mu \mathrm{m} ; 67=50 \mu \mathrm{m} ; 61,63,65,66=20 \mu \mathrm{m}$; $64=10 \mu \mathrm{m} ; 62=5 \mu \mathrm{m}$.

to genital opening, near $a d_{3}$; setae $a g, a d_{3}, a d_{2}, a d_{1}$, more or less same shape and length; anal plate polyhedral, sharply tipped with two pairs of anal setae. Polyhedral depressions (dep) situated laterally to genital and anal zones, between openings. Subcapitulum diarthric; large depression at lateral level of subcapitulum (Figure 68 indicated by - ).

Legs. Setal formulae I (1-2-2-2-15-1) (1-2-2); II (1-3-3-3-15-1) (1-12); III (2-3-1-2-14-1) (1-1-0); IV (1-2-2-2-12-1) (0-1-0).

Remarks. Zimbabweae kenyaensis sp. nov. is closely related to Zimbabweae pluosiae, but a series of differences exist between them. These species are very complex and SEM is indispensable in facilitating their study. Principal differences are found in the prodorsal zone: p.p.p differ in shape; p.p.d.2 large; lateral external I.p.r with several different structures; promontories in the zone of in setae are triangular (indicated by large white dot), separated by a furrow from those that are rounded polyhedral (indicated by $\downarrow$ ). Foveate zone anterior to CSO. Notogaster, c.Y.s anterior extension differ in shape, transversal promontories on zone anterior to $c_{1}$ insertion extend to prm Im; bo.ri with external furrow. Ventral region: epimeral zone with large promontories; setae ad, ag, differ in shape to Z. pluosiae.

\section{Discussion}

\section{Deposition of type species}

According to the first of the series of papers by Balogh and Mahunka (1969a; Acari: Oribatids collected during the second expedition, I), as indicated in page 2, type material was deposited in the Hungarian Natural History Museum, Budapest: "The Holotypes and the greater part of the Paratypes are deposited in the Zoological Collection of the Hungarian Natural History Museum, Budapest; one Paratype each, whenever it has been possible to do so, forwarded to the collections of Dr. J. Aoki, Tokyo; Dr. E. Piffl, Vienna; Dr. A. Rajski, Poznan; and Dr. T.A. Woolley, Louisiana". In the second paper (Balogh and Mahunka 1969b, Acari: Oribatids collected by the second expedition, II), page 31 reads as "The type-material of the described taxa is deposited as itemized in the preceding publication.*", and on 

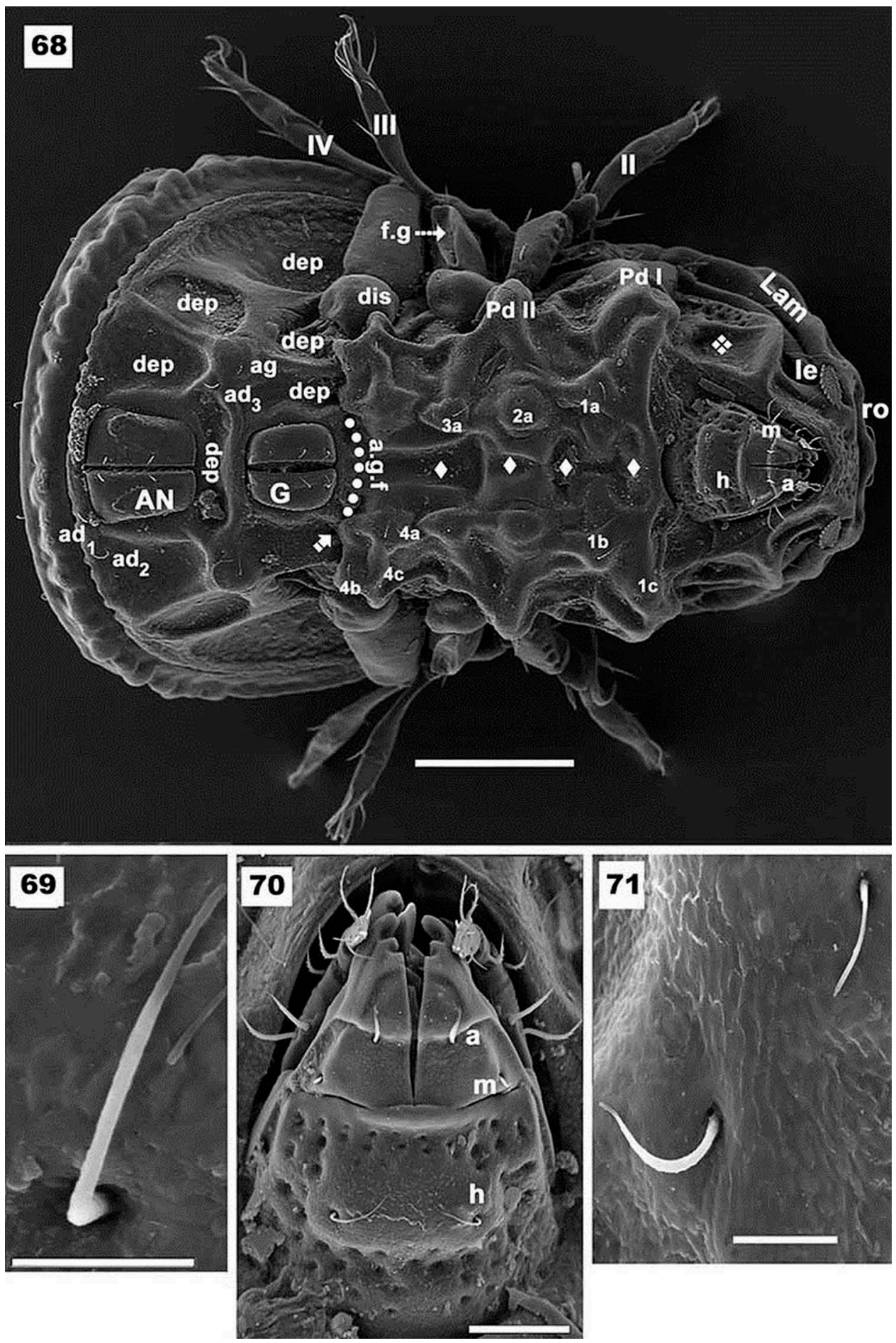

Figure 68-71. Zimbabweae kenyaensis sp. nov. Adult female, SEM observations. 68. ventral view; 69. epimeral setae 3a; 70. subcapitulum, ventral; 71. Ag-ad setal zone. Abbreviations: see section on "Material and methods". Scale bar: $68=100 \mu \mathrm{m} ; 69=20 \mu \mathrm{m} ; 70=10 \mu \mathrm{m} ; 71=5 \mu \mathrm{m}$.

page 48, regarding the type material of Phyllocarabodes octogonalis n. sp.: "Material examined: 1 ex. (Holotype: 0-606-68): No. 459-1. 1. ex. Paratype: 0-607-68): from the same locality".

Though not clearly stated, we thus deduced that the material was deposited in the Hungarian Natural History Museum, Budapest. However, our subsequent enquiries to this museum regarding a loan of this material resulted in a negative reply.

We spent many years searching for specimens resembling the type and recently, in samples from Costa Rica, we obtained interesting material similar to the type species of Phyllocarabodes. In the following, we analyse information about Carabodidae relating to the genus Carabodes. Subsequently, we supply a redefinition of the genus Phyllocarabodes, compare it to Carabodes, and provide our opinion on its taxonomy.

\section{Family Carabodidae, genus Carabodes}

The genital setal formula provided for Carabodes by Grandjean 1949, was (1-2-4-4). Subsequent studies by Andre (1975), Bellido (1978) and Ermilov (2011) confirmed this formula.

While Mahunka (1986) did not record two pairs of aggenital setae in any carabodid genera, Reeves and Behan-Pelletier (1998) provided a detailed redefinition of Carabodes, and found two pairs of aggenital setae in some species. The following species share this character state: $C$. brevis Reeves, $C$. erectus Reeves, $C$. falcatus Jacot, C. phylliformis Reeves, C. polyporetes Reeves, C. gibbiceps Berlese, C. cherokee Reeves, C. clavatus Jacot, C. niger Banks, C. coweetaensis Reeves, C. nantahalaensis Reeves, C. interruptus Reeves and C. floridus Berlese (Reeves \& Behan-Pelletier, 1998). 


\section{Post-embryonic development}

Information about immatures was obtained from Grandjean (1949, 1953) and André (1975) on Carabodes labyrinthicus; Bellido (1978) on C. willmanni; Reeves (1992) on C. erectus; Reeves and BehanPelletier (1998) and Ermilov (2011) on C. subarcticus.

We conclude that preceding authors (Grandjean 1949; 1953; André 1975; Bellido 1978; Reeves 1992, 1997; Reeves and BehanPelletier 1998) provided a good general overview of Carabodes and its principal characteristics and variations, but considered Pentabodes and Phyllocarabodes (amongst others) as separate taxa.

\section{Genus Phyllocarabodes}

The taxonomy of Phyllocarabodes Balogh \& Mahunka 1969 is complicated by an incomplete original description, and its unexplained inclusion in Carabodes as subgenus by Subías (2004 updated 2017) seemingly without study of the type material or additional specimens.

The taxonomy of Pentabodes, Antillobodes and Phyllocarabodes is confusing as indicated by the following: Mahunka, in his revision of the family Carabodidae in 1986, redescribed Pentabodes and Phyllocarabodes as different genera. Subías 2004 (until 2015) indicated "Carabodes (Phyllocarabodes) Balogh J \& Mahunka, 1969b (5 spp.)(=Antillobodes Mahunka, 1985) (=Pentabodes P. Balogh, 1984 "sin. nov."), without any further explanation.

Synonomy of Phyllocarabodes, Pentabodes and Antillobodes will be studied and discussed in a future paper. We have studied the type material of Antillobodes, but to date have been unable to obtain type material of Pentabodes, though we anticipate specimens among material collected in Colombia, housed in the Collection of the Museum National d'Histoire Naturelles (MNHN, Paris).

\section{Taxonomy of Phyllocarabodes}

The description of Phyllocarabodes octogonalis Balogh \& Mahunka $1969 \mathrm{~b}$ included only two figures (their Figure 34 and 35), and the captions to the figures only state: "34-35: Phyllocarabodes octogonalis n. sp.". Figure 34 is a dorsal view, but Figure 35 is of a notogastral or prodorsal seta (Balogh and Mahunka 1969b). Based on this incomplete description, the following problems arise when analysing further data on Ph. octogonalis:

The ornamentation of $P h$. octogonalis was discussed by Balogh $\mathrm{P}$. (1986) in his description of Ph. ornatus, and a comparison is given of the ornamentation of these two species. Balogh (1986) mentioned a tuberculate ornamentation of $P h$. octogonalis in his text and figures whereas Mahunka depicted and described Ph. octogonalis with a smooth surface. Hence the true nature of the surface is unclear.

Prodorsum and prodorsal setae. In Balogh and Mahunka (1969b), Figure 34 shows an interesting particularity: the dotted parallel lines behind in setae. We consider these lines to represent the elevated prodorsal longitudinal ridge (p.r.l) found between in setae and posterior zone of prodorsum (present paper: Figures 1 and 6, 6' indicated by p.r.l and - Balogh P. (1986) did not refer to this structure in his text, but in Figure 5 of $P h$. octogonalis, a sigmoid line was added behind the in setae. Mahunka (1986) indicated: "Prodorsum: lamellae with sharp cuspis, rostral setae thin, arising near to them, lamellar seta phylliform, originating in the interlamellar area". In their description, Balogh and Mahunka (1969b) stated: "Hairs ro and la narrowly, hairs in widely, phylliform". However, in illustrations, two pairs of setae are visible (in and ro), but not le. From Mahunka (1986) it is unclear if and where in setae were observed. Balogh P. (1986) also did not mention these setae in his comparison of Ph. octogonalis and Ph. ornatus.

Balogh and Mahunka (1969b) as well as Mahunka (1986) gave only vague information on interlamellar, lamellar and rostral setae which makes it difficult to homologize the setae as they show different positions in the different species
The situation of notogaster and notogastral setae is treated very superficially by Balogh and Mahunka (1969b), Mahunka (1986) and Balogh (1986), providing limited information on notogastral setae and not providing any discussion regarding the relative positions of the setae, nor of the characteristics of the notogaster (see section on "Conclusion").

Balogh and Mahunka (1969b) gave an epimeral formula of 1-1-33 while Mahunka (1986) provided a formula of 2-1-3-3. We doubt the existence of the second seta on epimeron I as indicated by Mahunka (1986) as the position of these setae is very particular and unusual.

In Mahunka (1986), the text and figures indicate two setae on the first epimere (setae indicated on Figure 62), and in Figure 63 a large seta situated on Pd.I, which was not observed by Balogh and Mahunka (1969b), nor by Balogh P. in 1986, but included by Mahunka (1986). Six pairs of genital setae are consistently observed in all three species of the genus Phyllocarabodes (Ph. octogonalis, Ph. ornatus, Ph. costaricensis).

Ten pairs of notogastral setae are observed in Phyllocarabodes, but with an unusual distribution. To provide notation for these setae, it is necessary to study ontogenetic development (Grandjean 1953; Travé 1964). Setal distribution is not related to the setal distribution of the genus Carabodes.

Genital formulae of Phyllocarabodes and Carabodes cannot be compared as ontogenetic studies of Phyllocarabodes are lacking.

In Phyllocarabodes, part of the notogaster is "light bulb-shaped", starting slightly behind the d.sj and extending to the posterior notogastral marginal setal zone. This zone is surrounded laterally by s.c that posteriorly is nearly erased or very flat, and is not clearly discernible (Figures 1 and 27) (present paper). This zone is tuberculate in Ph. octogonalis and Ph. ornatus (sensu Balogh P. 1986) and displays foveate microsculpture in Ph. costaricensis. The disposition of the notogaster posterior to the elevated zone is very different to that observed in known species of Carabodes. The shape of the notogaster and elevated zone can be compared to Figures 3, 5 and 8 of C. chandleri in Reeves 1992; C. erectus Figures 18 and 19 in Reeves 1992; C. interruptus Figures 26 and 28 in Reeves 1992; C. pentasetosus Figures 34 and 36 in Reeves 1992; C. labyrinthicus (Michael); C. rugosior Berlese; C. granulatus Banks Figures 39, 40 and 41, respectively, in Reeves and Behan-Pelletier (1998).

In Phyllocarabodes, the zone where h.ap and bo overlaps is distinct, as the anterior part of the h.ap is perfectly embedded in the posterior part of bo. This differs from that in Carabodes and can be compared to Carabodes hoh (Reeves \& Behan-Pelletier 1998) (Figures 36 and 42) and C. colorado (Reeves \& Behan-Pelletier 1998) (Figure 18) to observe the difference. In Phyllocarabodes, the bothridium (Figure 35, present paper) is distinct from that in Carabodes: the opening is directed downwards, mouse-ear shaped and incomplete, with smooth particular bo.ri and large bo.to.

These profound differences in body shape clearly support the idea that Phyllocarabodes is a distinct genus and not just a subgenus of Carabodes. We therefore redefine the genus as follows.

\section{Redefinition: Phyllocarabodes}

Elongate animals. Prodorsum elongate, with parallel ridges situated at level of in setae; extending from close to d.sj and exceeding in setal insertion level; ro setae longer than in; le setal insertion anterior to ro setal insertion; ventral tutorial zone dentate; $P d$ I medium-sized, $P d$ II very small, dis tiny, hardly discernible. Ten pairs of notogastral setae with particular distribution (notation cannot be accurately provided without ontogenetic studies); central zone of notogaster rounded or "light bulb-shaped", partially surrounded by s.c; s.c partially erased or flat posterior to elevated central zone; elevated notogastral zone microsculpture differing from rest of notogaster; epimeral setal formula 1-1-3-3; longer epimeral setae; $3 b, 3 c$ adjacent; six pairs of genital setae.

We consider Phyllocarabodes differentiated from Carabodes based on important differences in: shape of prodorsum and notogaster, disposition of prodorsal and notogastral setae (very different to 
Carabodes). All three known species of Phyllocarabodes have six pairs of genital setae.

\section{Acknowledgements}

We express much gratitude to Dr Peter Schwendinger, Curator of Geneva Museum, and the Geneva Museum, for extraordinarily kind assistance and collaboration, which allowed us to conduct this study, as well as to Dr Valerie Behan-Pelletier, for providing invaluable comments which greatly improved this manuscript. This work is based on research supported in part by the National Research Foundation of South Africa (UID) 85288. Any opinion, findings and conclusions or recommendations expressed in the manuscript are those of the authors and therefore the NRF does not accept any liability in regard thereto.

\section{Disclosure statement}

No potential conflict of interest was reported by the authors.

\section{Funding}

This work is based on research supported in part by the National Research Foundation of South Africa (UID) 85288.

\section{ORCID}

Nestor Fernandez (D) http://orcid.org/0000-0003-1071-5547

Pieter Theron (iD http://orcid.org/0000-0003-1344-2687

\section{References}

Alberti G, Fernandez N. 1988. Fine structure of a secondarily developed eye in the fresh water moss mite, Hydrozetes lemnae (Coggi 1899) (Acari: Oribatida). Protoplasma. 146:106-117.

Alberti G, Fernandez N. 1990a. Aspects concerning the structure and function of the lenticulus and clear spot of certain oribatids (Acari: Oribatida). Acarologia. 31:65-72.

Alberti G, Fernandez N. 1990b. Fine structure and function of the lenticulus and clear spot of Oribatids (Acari: Oribatida). In: Andre HM, Lions $\mathrm{J}-\mathrm{C}$, editors. L'ontogènese et le concept de stase chez les arthropodes. Wavere: Agar. p. 343-354.

Alberti G, Fernandez N, Coineau Y. 2007. Fine structure of spermiogenesis, spermatozoa and spermatophore of Saxidromus delamarei (Saxidromidae, Actinotrichida, Acari). Arthropod Structure Development 36:221-231.

Alberti G, Fernandez N, Kümmel G. 1991. Spermatophores and spermatozoa of oribatid mites (Acari: Oribatida). Part II. Functional and systematical considerations. Acarologia. 32:435-449.

Alberti G, Norton R, Adis J, Fernandez N, Franklin E, Kratzmann M, Moreno A, Ribeiro E, Weigmann G, Woas S. 1997. Porose integumental organs of oribatid mites (Acari: Oribatida). Zoologica. 48:33-114.

André H. 1975. Observation sur les Acariens corticoles de Belgique. - fondation Universitaire Luxembourgeoise. Série Notes de Recherches. 4:5-31.

Balogh J, Mahunka S. 1969a. The zoological results of the hungarian soil zoological expeditions to South America* 10. Acari: oribatids from the material of the second expedition, I. Acta Zoologica Academiae Scientiarum Hungaricae. 15:1-21.

Balogh J, Mahunka S. 1969b. The zoological results of the Hungarian soil zoological expeditions to South America* 11. Acari: oribatids from the material of the second expedition, II. Opuscula Zoologica Budapest. 9:30-69.

Balogh P. 1984. Oribatid mites from Colombia II (Acari). Acta Zoologica Hungarica. 30:315-326.

Balogh P. 1986. On the Genus Phyllocarabodes Balogh \& Mahunka, 1969 (Acari, Oribatei). Opuscula Zoologica Budapest. 22:59-62.
Bellido A. 1978. Développement postembryonnaire de Carabodes willmanni Bernini 1975 (Acari, Oribatei). Acarologia. 20:419-432.

Ermilov S. 2011. The Biology of the Development of the Oribatid Mite Carabodes subarcticus (Acari, Carabodidae) (Original Russian Text). Zoologicheskii Zhurnal. 90:665-673.

Evans G. 1992. Principles of acarology. Wallingford (UK): C.A.B International Cambridge. p. 563.

Fernandez N, Alberti G, Kümmel G. 1991. Ultrastructure of the spermatophores and spermatozoa of some Oribatid mites (Acari: Oribatida) Part I. Fine structure and histochemistry. Acarologia. 32:261-286.

Fernandez N, Theron P, Leiva S, Rollard C, Tiedt L. 2014a. Revision of the family Carabodidae (Acari: Oribatida) VI. Mangabebodes kymatismosi gen. nov., sp. nov. and Antongilibodes paulae gen. nov., sp. nov. from Madagascar. International Journal of Acarology 40:296-319.

Fernandez N, Theron P, Rollard C. 2013a. The family Carabodidae (Acari: Oribatida) I. Description of a new genus, Bovicarabodes with three new species, and the redescription of Hardybodes mirabilis Balogh, 1970. International Journal of Acarology 39:26-57.

Fernandez N, Theron P, Rollard C. 2013c. Revision of the family Carabodidae (Acari: Oribatida) IV. Afticarabodes anjavidilavai gen. nov., sp. nov., Rugocepheus joffrevillei sp. nov. and redefinition of the genus Rugocepheus Mahunka, 2009. International Journal of Acarology. 39:462-480.

Fernandez N, Theron P, Rollard C, Leiva S. 2014b. The family Carabodidae (Acari, Oribatida) VIII. The genus Machadocepheus (first part) Machadocepheus leoneae sp. n. and Machadocepheus rachii sp. n. from Gabon. Zookeys 456:1-28.

Fernandez N, Theron P, Rollard C, Leiva S. 2016. Revision of the family Carabodidae (Acari: Oribatida) XI. Congocepheus kardiae sp. nov. and Zimbabweae pluosiae gen. nov., sp.nov from the Republic of Zimbabwe. International Journal of Acarology 42:341-357.

Fernandez N, Theron P, Rollard C, Tiedt L. 2013b. Family Carabodidae (Acari: Oribatida) V. The genus Congocepheus Balogh, 1958 (Second Part), with a redescription of Congocepheus involutus Mahunka, 1997, and descriptions of two new species. Zoosystema. 35:551-579.

Grandjean F. 1949. Formules anales, gastronomiques, génitales, aggénitales du développement numérique des poils chez les Oribates. Bulletin Société Zoologique France. 74:201-225.

Grandjean F. 1953. Essai de classification des Oribates. Bulletin. France: Société Zoologique. 78:421-446.

Krantz G, Walter D. 2009. A manual of acarology. 3rd ed. Lubbock (TX): Texas Tech University Press. p. 807.

Mahunka S. 1985. Neue und interessante Milben aus dem Genfer Museum LVII. Oribatida Americana 9: antilles I (Acari). Revue suisse de Zoologie. 92:119-144.

Mahunka S. 1986. A survey of the family Carabodidae C. L. Koch, 1836 (Acari:Oribatida). Acta Zoologica Hungarica. 32:73-135.

Murley MR. 1951. Seeds of the Cruciferae of Northeastern North America. American Midland Naturalist. 46:1-81.

Reeves M, Behan-Pelletier V. 1998. The genus Carabodes (Acari: Oribatida: Carabodidae) of North America, with descriptions of new western species. Canadian Journal Zoology. 76:1898-1921.

Reeves R. 1992. Carabodes of the eastern United States and adjacent Canada (Acari: Oribatida: Carabodidae). Canadian Journal of Zoology. 70:2042-2058.

Reeves R. 1997. Adults and immatures of Yoshiobodes irmayi (Acari: Oribatida: carabodidae) from North America. Acarologia 1. 38:315-323.

Subías S. 2004. Listado sistemático, sinonímico y biogeográfico de los Ácaros Oribátidos (Acariformes, Oribatida) del Mundo (1758-2002). Graellsia. 60:3-305. (updated 2017).

Travè J. 1964. Importance des stases immatures des oribates en systématique et en écologie. Proceedings Ist International Congress of Acarology; Fort Collins, CO. p. 47-54.

Travé J, Vachon M. 1975. François Grandjean 1882-1975 (Notice biographique et bibliographique). Acarologia. 17:1-19. 